\title{
Retail Inventory Behavior and Business Fluctuations
}

THE enigmatic behavior of the U.S. economy during the 1980 recession makes it more imperative than ever that some of the mystery that surrounds inventory behavior be solved. On the surface, the economy seems to have reacted quite differently to what appear to be rather similar external shocks (principally, rapid increases in oil prices) in 1973-75 and in 1979-80. However, if one abstracts from inventory behavior and focuses on final sales, the two recessions look rather similar. Several observations confirm this. First, the briefest recession in U.S. history was also the first in which inventory investment did not swing sharply toward liquidation between the peak and the trough. Second, if one judges the contraction by real final sales instead of real GNP, the 1980 recession was actually far deeper than the "severe" $1973-75$ recession. ${ }^{1}$ And third, the way the 1980 recession was concentrated into a single quarter seems less unusual if one looks at real final sales instead of real GNP. In the 1973-75 reces-

I thank Danny Quah for exceptional research assistance. I also thank Gregory Mankiw and Leonard Nakamura for research assistance and Stephenie Sigall and Phyllis Durepos for quickly and efficiently typing the paper. I am grateful to members of the Brookings panel and to a number of colleagues for helpful discussions on this research. I apologize to those I leave out when I mention Angus S. Deaton, David Germany, Wayne Gray, F. Owen Irvine, Jr., Louis J. Maccini, Bennett T. McCallum, and Robert J. Shiller. The research was supported by the National Science Foundation and the Sloan Foundation, and was done mainly at the National Bureau of Economic Research.

1. Real GNP declined $\$ 60.7$ billion from peak to trough in the $1973-75$ recession, versus only $\$ 38.6$ billion in the 1980 recession. However, the respective declines in real final sales were $\$ 22.7$ billion and $\$ 40.8$ billion. 
sion, for example, fully 90 percent of the total peak-to-trough decline in real final sales happened in a single quarter (1974:4).

In a word, inventories hold the key to understanding why the 1980 recession was so different from previous ones.

Relative to its importance in business fluctuations, inventory investment must be the most underresearched aspect of macroeconomic activity. A hot topic in the 1950 s, research on inventory behavior apparently went out of style in the early 1960s and languished during the 1970s. But there was never any good reason for work on inventories to fall out of fashion. The importance of inventory movements in business cycles did not end in the early 1960s. Nor, despite Michael Lovell's best efforts, did economists develop such a well established and empirically validated theory of inventory investment that the case was closed. ${ }^{2}$ Yet research on inventories went out like high-buttoned shoes.

Worse yet, what little attention the profession has paid to inventories over the past two decades seems to have been misplaced. Both theoretical and empirical attention appears to have congealed around applying the production smoothing-buffer stock model to the study of manufacturers' inventories of finished goods. Yet, as I demonstrate below, finished goods held by manufacturers constitute one of the least important types of inventory. Furthermore, I argue that the underlying theoretical framework is probably inappropriate and inconsistent with the facts. Obviously this leaves both the microeconomics and macroeconomics of inventory behavior in a rather unsatisfactory state.

The structure of this paper naturally follows from the preceding remarks. First, some basic facts of inventory fluctuations in the U.S. economy are set out. This preliminary investigation (as well as data availability) leads me to concentrate on retail inventories instead of manufacturers' inventories of finished goods. Second, a variety of competing theories are examined in order to see which, if any, make sense in the light of the facts. Third, an alternative model of retail inventory investment is developed and compared with the traditional theory. Finally, empirical inventory equations are derived from this theory, and these equations are estimated econometrically and used to study recent inventory behavior.

2. Michael Lovell, "Manufacturers' Inventories, Sales Expectations, and the Acceleration Principle," Econometrica, vol. 29 (July 1961), pp. 293-314. 


\section{The Importance of Inventories in Business Cycles}

The overwhelming importance of inventory movements in business cycles is one of those basic facts that seems to be inadequately appreciated. Inventory investment is, on average, a tiny component of GNP (about 1 percent). Yet it has almost always accounted for a major share of the decline in GNP during recessions-and has often exceeded the decline in GNP as a whole, that is, real final sales have often risen during recessions.

\section{INVENTORIES IN RECESSIONS}

The top part of table 1 shows the relevant data for the seven postwar recessions. Inventory change has, on average, accounted for 101 percent of the peak to trough decline in real GNP; or, keeping score a different way, the average inventory change was 60 percent of the average GNP decline. $^{3}$

This pattern is not new. The bottom part of the table displays similar data for the interwar period and tells a similar story. In fact, real GNP actually increased from peak to trough in two of the five interwar recessions. Inventory investment, however, always declined.

The 1980 recession stands out as a sharp break with history. With the exception of the post-World War II adjustment period, during which inventories were replenished while production fell, the 1980 recession is the only one since World War I (and perhaps the only one since the American revolution) in which inventory investment moved countercyclically. Some possible reasons for this are explored at the end of the paper.

\section{DECOMPOSITION OF VARIANCE}

Recessions are obviously atypical periods, almost by definition. It is clear that inventories play a rather minor role in economic activity when

3. Note that the peaks and troughs are defined here by real GNP. They do not always correspond to official NBER dates. One common objection to data like those in table 1 is that other components of GNP might show a similarly dramatic pattern. They do not. In fact, the only component that comes close is fixed investment, which has been procyclical in all seven recessions. A table like table 1 for fixed investment would have entries in the third column ranging from a high of 95 percent to a low of 1 percent, and averaging only 55 percent. 
Table 1. Changes in GNP and in Inventory Investment in Recessions

\begin{tabular}{|c|c|c|c|}
\hline Period & $\begin{array}{l}\text { Change in } \\
\text { real GNP }\end{array}$ & $\begin{array}{l}\text { Change in } \\
\text { inventory } \\
\text { investment }\end{array}$ & $\begin{array}{l}\text { Change in inven- } \\
\text { tory investment } \\
\text { as a percentage } \\
\text { of change in } \\
\text { real GNP }\end{array}$ \\
\hline \multicolumn{4}{|c|}{ Postwar recessions (peak and trough) $\mathrm{b}$} \\
\hline $1948: 4-1949: 4$ & -7.1 & -13.0 & 183 \\
\hline $1953: 2-1954: 2$ & -20.2 & -9.2 & 46 \\
\hline 1957:3-1958:1 & -23.0 & -10.5 & 46 \\
\hline 1960:1-1960:4 & -8.6 & -18.0 & 209 \\
\hline 1969:3-1970:4 & -7.3 & -12.3 & 168 \\
\hline $1973: 4-1975: 1$ & -60.7 & -38.0 & 63 \\
\hline 1980:1-1980:2 & -38.6 & 2.2 & -6 \\
\hline \multicolumn{4}{|l|}{ Interwar recessions } \\
\hline $1920-21$ & -3.6 & -4.2 & 117 \\
\hline $1923-24$ & 1.5 & -3.7 & $\mathbf{c}$ \\
\hline $1926-27$ & 1.0 & -0.8 & e \\
\hline 1929-32 & -32.0 & -5.6 & 18 \\
\hline $1937-38$ & -3.1 & -2.9 & 94 \\
\hline
\end{tabular}

Source: Postwar data are from the national income and product accounts; interwar data are adapted from Moses Abramovitz, Inventories and Business Cycles (National Bureau of Economic Research, 1950), table 84, pp. 476-77.

a. Billions of 1972 dollars for postwar recessions, billions of 1929 dollars for interwar recessions.

b. Peaks and troughs of real GNP, not official dates of the National Bureau of Economic Research.

c. Real GNP rose during this recession.

the economy is expanding smoothly. A broader picture can be obtained of the importance of inventories in business fluctuations as follows. Define $Y_{t}$ as real GNP, $X_{t}$ as real final sales, and $N_{t}$ as real inventory stock at the beginning of the period. Then the GNP identity is

$$
Y_{t}=X_{t}+\left(N_{t+1}-N_{t}\right) .
$$

If all data are detrended and lowercase symbols are used to denote deviations from trend, the variance of GNP around trend for the 1947:21981:1 period can be decomposed as ${ }^{4}$

$$
\begin{gathered}
\operatorname{var}(y)=\operatorname{var}(x)+\operatorname{var}(\Delta n)+2 \operatorname{cov}(x, \Delta n) . \\
(678.3) \quad(514.4) \quad(43.9)
\end{gathered}
$$

4. Because of a strong a priori notion (based on observations of plotted data) that there was a break in the trend of most macro aggregates after the first OPEC shock, real final sales, real GNP, and real inventory stocks (not changes) were all 
Judging from equation 2, inventory fluctuations account for only 6.5 percent of GNP fluctuations about trend (but recall that inventory investment averages only about 1 percent of GNP). However, this calculation of the importance of inventories may understate their relevance for changes in GNP because there is a strong positive covariance between deviations of real final sales and real inventory investment from trend (the simple correlation is 0.38 ), and because quarterly deviations from trend are likely to be persistent. An alternative decomposition, which may be more sensitive to the importance of inventories for changes in output, can be obtained by taking the first difference of equation 1 and decomposing the variance of the growth of GNP for the same period as

$$
\begin{array}{ccc}
\operatorname{var}(\Delta Y) & \operatorname{var}(\Delta X)+\operatorname{var}\left(\Delta^{2} N\right)+2 \operatorname{cov}\left(\Delta X, \Delta^{2} N\right) . \\
(111.5) & (85.3) & (33.1)
\end{array}
$$

If one looks at equation 3, inventory fluctuations appear to account for a full 30 percent of the fluctuations in the growth of real GNP from quarter to quarter. This is an enormous amount for such a small component. Changes in final sales, however, are negatively correlated with changes in inventory investment, so that the direct contribution of inventory fluctuations may slightly overstate their importance.

A more disaggregated look at the variance of $y$ (or of $\Delta Y$ ) offers some lessons about the history of business fluctuations in the postwar United States. Tables 2 and 3 display disaggregated versions of equations 2 and 3 in which the final sales variable is divided into its main components: consumption expenditures, fixed investment, government purchases, and net exports. In each table, variances are reported in boldface on the diagonal, covariances above the diagonal, and correlation coefficients below it. These tables contain some fascinating facts.

detrended according to the following model of the trend component:

$$
\log Z_{t}=a_{0}+a_{1} T I M E+a_{2} D T I M E+\varepsilon_{t},
$$

where TIME is a linear time trend and DTIME is a linear time trend beginning at 1 in 1973:4 in quarterly data or October 1973 in monthly data. Estimation was by generalized least squares, allowing for second-order autocorrelation in $\varepsilon_{t}$. The antilogs of the fitted values from the detrending regressions were subtracted from the actual data to define the detrended data. Because the detrending of each series was done in logs independently, the identity (equation 1) does not hold exactly for the detrended data; but it comes close. 
Table 2. Decomposition of the Variance of GNP around Trend, 1947:2 through 1981:1 ${ }^{\text {a }}$

\begin{tabular}{|c|c|c|c|c|c|c|}
\hline & $G N P$ & $\begin{array}{c}\text { Inven- } \\
\text { tory } \\
\text { invest- } \\
\text { ment }\end{array}$ & $\begin{array}{l}\text { Con- } \\
\text { sumption } \\
\text { expendi- } \\
\text { ture }\end{array}$ & $\begin{array}{c}\text { Fixed } \\
\text { invest- } \\
\text { ment }\end{array}$ & $\begin{array}{l}\text { Govern- } \\
\text { ment } \\
\text { purchases }\end{array}$ & $\begin{array}{c}\text { Net } \\
\text { exports }\end{array}$ \\
\hline GNP & 678.3 & 99.1 & 233.2 & 206.0 & 198.9 & -66.4 \\
\hline Inventory investment & 0.58 & 43.9 & 34.7 & 37.5 & -3.5 & -10.7 \\
\hline Consumption expenditure & 0.64 & 0.37 & 199.1 & 112.2 & -139.4 & 12.2 \\
\hline Fixed investment & 0.79 & 0.56 & 0.79 & 101.4 & -36.8 & -12.8 \\
\hline Government purchases & 0.33 & -0.02 & -0.41 & -0.16 & $\mathbf{5 5 0 . 0}$ & -140.5 \\
\hline Net exports & -0.30 & -0.19 & 0.10 & -0.15 & -0.70 & 74.2 \\
\hline
\end{tabular}

Source: Author's calculations based on national income and product accounts.

a. Variances are displayed on the diagonal; covariances and correlation coefficients are shown above and below the diagonal, respectively.

Table 3. Decomposition of the Variance of Changes in GNP, 1947:3 through 1981:1 ${ }^{\mathrm{a}}$

\begin{tabular}{|c|c|c|c|c|c|c|}
\hline & $\Delta G N P$ & $\begin{array}{c}\Delta \text { Inven- } \\
\text { tory } \\
\text { invest- } \\
\text { ment }\end{array}$ & $\begin{array}{l}\Delta \text { Con- } \\
\text { sumption } \\
\text { expendi- } \\
\text { ture }\end{array}$ & $\begin{array}{c}\Delta \text { Fixed } \\
\text { invest- } \\
\text { ment }\end{array}$ & $\begin{array}{l}\Delta \text { Govern- } \\
\text { ment } \\
\text { purchases }\end{array}$ & $\begin{array}{l}\Delta N e t \\
\text { ex- } \\
\text { ports }\end{array}$ \\
\hline$\Delta \mathrm{GNP}$ & 111.5 & 29.6 & 43.2 & 32.9 & 5.3 & 0.5 \\
\hline$\Delta$ Inventory investment & 0.49 & 33.1 & -2.4 & 4.4 & -1.9 & -3.4 \\
\hline$\Delta$ Consumption expenditure & 0.71 & -0.07 & 32.9 & 15.9 & -1.5 & -1.7 \\
\hline$\Delta$ Fixed investment & 0.76 & 0.19 & 0.68 & 16.7 & -2.2 & -1.9 \\
\hline$\Delta$ Government purchases & 0.15 & -0.10 & -0.08 & -0.17 & 10.6 & 0.3 \\
\hline$\Delta$ Net exports & 0.02 & -0.22 & -0.11 & -0.17 & 0.04 & 7.1 \\
\hline
\end{tabular}

Source: Author's calculations based on national income and product accounts. a. See table 2 , note a.

Table 2 displays the decomposition of $\operatorname{var}(y)$-the variance of real GNP about trend. The most striking fact, though it is tangential to the concerns of this paper, is how much of the variance of $x$ is composed of the variance of government purchases. But compared with the variances about trend of consumption and investment (both of which are much larger components of GNP), the variance of inventory investment does not look so paltry as it did in equation 2. Furthermore, a strong positive covariation is apparent between $\Delta n$ and either consumption or investment. Thus inventory fluctuations are more significant than might appear from equation 2.

Inventory investment seems even more important in table 3 , which disaggregates equation 3. Inventory investment has the largest variance, 
Table 4. Decomposition of the Variance of Inventories, Quarterly, 1959-80

\begin{tabular}{|c|c|c|c|c|c|c|}
\hline $\begin{array}{l}\text { Inventory } \\
\text { component }\end{array}$ & $\begin{array}{l}\text { Inventory } \\
\text { level at } \\
\text { the end } \\
\text { of } 1980^{\mathrm{a}}\end{array}$ & $\begin{array}{c}\text { Percent } \\
\text { of total } \\
\text { level }\end{array}$ & $\begin{array}{l}\text { Variance } \\
\text { of inven- } \\
\text { tory in- } \\
\text { vestment }\end{array}$ & $\begin{array}{l}\text { Percent } \\
\text { of total } \\
\text { variance }\end{array}$ & $\begin{array}{c}\text { Variance } \\
\text { of change } \\
\text { in inven- } \\
\text { tory in- } \\
\text { vestment }\end{array}$ & $\begin{array}{l}\text { Percent } \\
\text { of total } \\
\text { variance }\end{array}$ \\
\hline Total nonfarm & 297.6 & 100.0 & 44.45 & 100.0 & 36.90 & 100.0 \\
\hline Manufacturers & 145.0 & 48.7 & 15.76 & 35.5 & 10.58 & 28.7 \\
\hline Materials and supplies & 51.0 & 17.1 & 5.28 & 11.9 & 5.70 & 15.4 \\
\hline Work in progress & 50.4 & 16.9 & 3.87 & 8.7 & 2.99 & 8.1 \\
\hline Finished goods & 43.5 & 14.6 & 2.10 & 4.7 & 2.40 & 6.5 \\
\hline Retail trade & 64.6 & 21.7 & 9.07 & 20.4 & 14.56 & 39.5 \\
\hline Automobiles & 15.3 & 5.1 & 4.57 & 10.3 & 9.91 & 26.9 \\
\hline Wholesale trade & 64.7 & 21.7 & 3.39 & 7.6 & 4.77 & 12.9 \\
\hline All other & 23.4 & 7.9 & 1.22 & 2.7 & 1.82 & 4.9 \\
\hline All covariance terms & $\ldots$ & $\ldots$ & 15.01 & 33.8 & 5.17 & 14.0 \\
\hline
\end{tabular}

Source: Author's calculations based on national income and product accounts.

a. In billions of 1972 dollars, seasonally adjusted:

b. From 1959:2 through 1980:4.

c. From 1959:3 through 1980:4.

measured in quarter-to-quarter changes, of any GNP component, which is quite surprising when one recalls that, on average, consumption spending is about seventy times as large as inventory investment. The case is probably made; inventories really do matter in business fluctuations.

\section{INVENTORY FLUCTUATIONS BY TYPE}

A natural next question to ask is, which sorts of inventories are responsible for all this fluctuation? From 1959 on there are good data on real inventories by sector and by stage of processing. Table 4 reports a decomposition of the overall variance of both nonfarm inventory investment $(\Delta N)$ and the change in nonfarm inventory investment $\left(\Delta^{2} N\right)$. Two results are striking. First, manufacturers' inventories of finished goods, the component of inventories that has received the lion's share of both theoretical and empirical attention, are the least important type of inventories in cyclical fluctuations. Second, retail inventories are the most important component of total inventories in terms of cyclical variability. Although less important than total manufacturing inventory investment in accounting for variations around trend, retail inventory investment is far more important than any of the three components of manufacturers' inventories. And when it comes to the variance of changes in inventory 
investment, retail inventories are more important than even total manufacturing inventories. ${ }^{5}$

\section{THE INVENTORY-SALES RATIO AS A CYCLICAL INDICATOR}

The most commonly used indicator of the state of inventory equilibrium or disequilibrium is the ratio of inventories to sales in manufacturing and trade. This ratio moves countercyclically, rising in recessions. But the meaning of this empirical regularity is far from clear.

Letting $N^{*}$ denote desired inventories, the ratio can be expressed as

$$
\frac{N}{X}=\frac{N}{N^{*}} \times \frac{N^{*}}{X}
$$

In most journalistic interpretations of the business cycle, $N^{*} / X$ is regarded as relatively constant, and observed fluctuations in $N / X$ are taken to reflect changes in inventories relative to desired inventories, that is, inventory disequilibrium. In this view, $N / N^{*}$ rises in recessions because firms accumulate unwanted stocks and falls in booms because sales outstrip expectations and stocks are drawn down.

An opposing interpretation is that $N / N^{*}$ is always approximately unity, with firms always keeping their inventories more or less where they want them. In this view, it is $N^{*} / X$ that rises in recessions and falls in booms. Why? Suppose desired inventories depend on long-run average sales, $X^{*}$, and $N^{*} / X^{*}$ is constant. Then, in a recession, $X$ falls relative to $X^{*}$, so $N^{*} / X$ rises. For similar reasons, $N^{*} / X$ falls in a boom. Movements in $N / X$, in this view, do not indicate inventory disequilibrium. These different interpretations of the same basic fact lead to strikingly different specifications and interpretations of econometric equations explaining inventory investment, and these are explored below.

\section{The Production Smoothing-Buffer Stock Model of Inventory Behavior}

Firms hold inventories for transactions, speculative, or precautionary reasons. A clothing store must display goods on the racks to sell them; a furniture store needs floor samples to show customers (both

5. However, a good deal of the variability of retail inventory investment comes from the automobile industry, where the distinction between retail inventories and manufacturers' inventories of finished goods may not be very sharp. 
transactions motives). Manufacturers may hold stocks of raw materials because they think their prices will rise (speculative motives). A department store holds inventories to avoid running out of stock and therefore losing customers (a precautionary motive). There are other motives as well. For example, manufacturers may hold inventories of finished goods because they want to smooth production in the face of fluctuating sales. Manufacturers may find inventories of work in progress useful in scheduling production.

Although it is easy to invent micro theoretic rationales for holding inventories, only one model has provided the micro foundations for any substantial amount of empirical work. That model is the production smoothing-buffer stock model, which was first extensively used in empirical work by Lovell and has provided the basis for most empirical work since then. ${ }^{6}$

Production smoothing arises when sales are variable over time and marginal costs of production are rising; it has nothing inherently to do with uncertainty. Even without randomness anywhere, firms with variable sales and rising marginal costs will find it optimal to smooth production relative to sales, accumulating inventories when demand is weak and liquidating inventories when demand is strong. In addition to being variable, sales may also be random. In this case a buffer-stock element arises: firms may hold inventories against the contingency that demand will be unexpectedly high.

The production smoothing-buffer stock model is typically represented empirically by the following stock-adjustment equation:

$$
N_{t+1}-N_{t}=\lambda\left(N_{t}^{*}-N_{t}\right)-\beta\left(X_{t}-X_{t}^{e}\right)+\epsilon_{t},
$$

where $X_{t}^{e}$ is expected sales and $\epsilon_{t}$ is a random error. That the first term represents the production-smoothing motive while the second represents the buffer stock can be seen by using the identity (equation 1 ) to rewrite 4 as

$$
Y_{t}=X_{t}^{e}+(1-\beta)\left(X_{t}-X_{t}^{e}\right)+\lambda\left(N_{t}^{*}-N_{t}\right)+\epsilon_{t} .
$$

The first two terms reflect the use of inventories as a buffer stock. If production decisions are made before actual sales are known and $N_{t}=N_{t}^{*}$, firms will produce $X_{t}^{e}$. Under these circumstances, $\beta$ will be

6. Lovell, "Manufacturers' Inventories." 
unity; inventory movements will completely buffer production from sales surprises. If, however, firms desire and are able to alter production plans within the period as they learn about $X_{t}, \beta$ can be less than unity. In the extreme case, $\beta=0$, production reacts fully to realized sales, and inventories do not serve as a buffer at all. Thus the size of $\beta$ measures the degree of buffering. The value of $\beta$ obviously should depend, among other things, on the length of the observation period.

The last term in 5 represents intended inventory accumulation, and production-smoothing considerations will result in a value of $\lambda$ between 0 and 1 , which is what leads to the stock-adjustment feature. ${ }^{7}$

To make the model represented by equation 4 operational, $N_{t}^{*}$ is typically expressed as a linear function of $X_{t}$ or $X_{t}^{e}$ or a related variable, and some proxy for expectations is introduced. When this is done, the following sorts of empirical results typically emerge from quarterly data. ${ }^{8}$

First, the estimated coefficient $\beta$ is practically zero. This means that sales surprises do not affect inventories, so that such surprises must have nearly one-for-one effects on output. That is, the estimated coefficient suggests that the buffer stock motive is unimportant.

Second, the coefficient $\lambda$ is normally so small that it seems implausible to interpret it as a parameter measuring speed of adjustment. When even the biggest swings in inventories amount to no more than one or two weeks of sales, it is hard to understand why $\lambda$ would be around 0.1 or 0.2 , that is, why only 10 or 20 percent of the deviation of inventories from target would be corrected within a quarter. ${ }^{9}$

A third piece of evidence, which is difficult to reconcile with the notion of production smoothing, is the observation that the variance of $Y$ over time exceeds that of $X$ in a wide variety of sectors and subsectors, and also in the entire economy.

Finally, as just shown, retail inventories play a more prominent role in cyclical fluctuations than manufacturers' inventories of finished goods, for which the production smoothing-buffer stock model was designed.

The stock-adjustment model can be applied to retailing, with empirical

7. See Alan S. Blinder, "Inventories and Sticky Prices: More on the Microfoundations of Macroeconomics," American Economic Review, forthcoming.

8. See Martin Feldstein and Alan Auerbach, "Inventory Behavior in DurableGoods Manufacturing: The Target-Adjustment Model," BPEA, 2:1976, pp. 35196; and F. Owen Irvine, Jr., "Retail Inventory Investment and the Cost of Capital," American Economic Review, vol. 71 (September 1981), pp. 633-48.

9. This point was emphasized by Feldstein and Auerbach. See ibid. 
results that in general turn out to be quite similar to those for manufacturing. ${ }^{10}$ The problem is that a persuasive rationale for partial inventory adjustment by retailers is lacking. The variable $Y_{t}$ for a retailer represents deliveries from manufacturers, and it seems unlikely that the typical retailer faces rising marginal costs of purchasing. In fact, because of quantity discounts and related phenomena, retailers probably face constant or declining marginal costs. Under such conditions, the productionsmoothing model falls apart. Just as a manufacturer with declining marginal costs will want to produce output in large lots (production runs), a retailer with falling marginal costs will want to "bunch" orders to reduce costs.

\section{The $S, s$ Model of Inventory Behavior}

This simple idea is the basis for the model I explore in this paper. In particular, suppose there are no quantity discounts but there is a substantial fixed cost of placing an order or receiving a delivery. That is, suppose a retailer's cost of acquiring $Y_{t}$ units from the manufacturer in period $t$ is given by

$$
\begin{array}{ll}
C\left(Y_{t}\right)=A+c Y_{t} & \text { if } Y_{t}>0 \\
C\left(Y_{t}\right)=0 & \text { if } Y_{t}=0,
\end{array}
$$

where $A$ is fixed cost and $c$ is (constant) marginal cost.

This cost function has been studied extensively in the operations research literature. It leads to an inventory strategy called the " $S, s$ rule," meaning that inventories are allowed to dwindle to some minimum level, $s$, at which time a purchase restores inventories to their maximum level, $S$. The basic idea behind the $S, s$ strategy is that, owing to the fixed costs, it pays for a firm to place fewer orders, make each order larger, and store more inventories than it would if fixed costs did not exist.

There are many reasons for such a cost structure. Some originate with

10. See Michael C. Lovell, "Department Store Inventory, Sales, Order Relationships," in J. S. Duesenberry and others, eds., The Brookings Model: Some Further Results (Amsterdam: North-Holland, 1969), pp. 18-38; and Irvine, "Retail Inventory Investment and the Cost of Capital," and "The Influence of Capital Costs on Inventory Investment: Time Series Evidence for a Department Store," Quarterly Review of Economics and Business, forthcoming. 
the retailer. There may be transportation and warehousing costs that are lumpy (for example, it may cost little more to receive a truckload of television sets than to receive a dozen). Bookkeeping costs probably depend far more on the number of orders than on the quantity of goods ordered. Perhaps most important, and most often ignored, is the scarcity of managerial time and attention. One way to economize on this scarce resource is to place orders less frequently and make each one larger.

Although somewhat contrary to standard neoclassical economic thought, this factor is probably pervasive and important. Why, for example, when workers take stationery from the office supply cabinet, do they not just take what they need for the next day (or hour or minute)? It is not because there is a large transportation cost or because there is bookkeeping to do. Rather, it is because each trip to the cabinet occupies some of the workers' time-valuable time that they could spend on something else. The same is certainly true for business managers. ${ }^{11}$

Other sources of fixed costs originate with manufacturers. They, too, may incur substantial costs in processing an order, getting the goods together, and shipping them out. They certainly face the same scarcity of managerial time and energy that retailers do. These factors may induce the manufacturer to adopt a pricing structure like that represented in equation 6. Indeed, the fact that most manufacturers refuse to deal directly with consumers placing small orders suggests that the fixed costs, elusive as they may be, are probably very important in practice. Thus the cost technology that underlies the $S, s$ model is appealing on a priori grounds. The fixed cost, $A$, may represent a fee the manufacturer charges, a cost the retailer incurs, or both.

\section{B ACKGROUND}

The $S, s$ model, which is allegedly in common use in industry, has a long and venerable history in the operations research and management science literature. The interest of economists in $S, s$ inventory strategies seems to have been sparked by the pioneering paper of Arrow, Harris, and Marschak. Many articles on specific $S, s$ models were published in the ensuing years, and Scarf finally proved that fixed costs of ordering

11. Indeed, Michael Lovell suggests to me that part of the appeal of the $S, s$ inventory strategy in practice is that, once the trigger points $S$ and $s$ are set, there is little need for managerial attention and decisionmaking. 
make $S, s$ rules of one type or another optimal under a wide variety of circumstances. ${ }^{12}$

Because I make use of several examples of $S, s$ models with particular simplifying assumptions, it is worth emphasizing that the basic $S, s$ rule emerges as the optimal inventory strategy under a wide variety of assumptions about such matters as what is random and what is deterministic, when information on sales becomes available to firms, whether it is possible to accept unfilled orders, whether there are delivery lags, whether time is continuous or discrete, and so on. However, three features of the firm's economic environment seem to be critical to the optimality of the $S, s$ rule. First, the cost of acquiring goods from the manufacturer must be precisely like that given in equation 6 . It can be shown that this equation does in fact lead to the $S, s$ rule, and also that such a rule will not be optimal if either $A$ equals zero or $c$ is not constant. ${ }^{13}$ Second, a firm's sales and prices must be exogenous. To my knowledge, no $S, s$ models have been developed in which the firm can exercise control over its sales-for example, by varying its selling price. Furthermore, it is doubtful that $S, s$ behavior is optimal once the probability distribution of sales comes under the firm's control (even though the fixed cost element will continue to induce firms to order infrequently). Third, the parameters underlying the firm's optimization problem (its cost functions, probability distribution of sales, and so on) must be constant through time. Every $S, s$ model that I know about has been solved under the assumption of stationarity, including the assumption that sales are independently and identically distributed over time. Such assumptions are very stringent and empirically inaccurate. For example, aggregate retail sales are highly serially correlated, and it would be surprising indeed if this serial correlation disappeared at the level of the firm.

12. See G. Hadley and T. M. Whitin, Analysis of Inventory Systems (Prentice Hall, 1963); Kenneth J. Arrow, Theodore Harris, and Jacob Marschak, "Optimal Inventory Policy," Econometrica, vol. 19 (July 1951), pp. 250-72; Kenneth J. Arrow, Samuel Karlin, and Herbert Scarf, eds., Studies in Applied Probability and Management Science (Stanford University Press, 1962); K. J. Arrow, S. Karlin, and H. Scarf, Studies in the Mathematical Theory of Inventory and Production (Stanford University Press, 1958); and H. Scarf, "The Optimality of (S,s) Policies in the Dynamic Inventory Problem," in K. J. Arrow, S. Karlin, and Patrick Suppes, eds., Mathematical Methods in the Social Sciences, 1959 (Stanford University Press, 1960), pp. 196-202.

13. An appendix showing this and other technical results is available from the author upon request. 
It is easy to see what happens qualitatively in a nonstationary environment. It can be shown that if the underlying parameters vary over time, the firm will adhere to an $S_{t}, s_{t}$ strategy in which the trigger points change each period. ${ }^{14}$ For example, if sales disturbances are serially correlated, information on past sales will be used in setting $S_{t}$ and $s_{t}$ for this period.

\section{AN EXAMPLE}

To understand the factors determining $S$ and $s$, it is helpful to have an example of an explicit solution. None exists for the nonstationary case, which is the case of greatest empirical interest. Nonetheless, a specific example will help clarify the nature of the $S, s$ trigger points. Hadley and Whitin show that the following square root rule is optimal or approximately optimal in a variety of different models in which firms have exogenous (but random) sales and minimize long-run costs in a stationary environment: ${ }^{15}$

$$
\begin{aligned}
S-s & =\sqrt{\frac{2 \bar{X}}{r+d}\left[\frac{A}{c}+\frac{\delta}{c} q(s)\right]} \\
1-H(s) & =\frac{S-s}{\bar{X}} \cdot \frac{c}{\delta}(r+d),
\end{aligned}
$$

where

$$
\begin{aligned}
\bar{X} & =\text { mean sales } \\
H(X) & =\text { cumulative distribution function of sales } \\
H(s) & =\text { the probability that sales will be less than } s \text { in a given period } \\
r & =\text { real rate of interest } \\
d & =\text { storage cost per period (as a percent) } \\
\delta & =\text { a penalty cost for having an order unfilled per unit } \\
q(s)= & \text { mean number of unfilled orders, which will depend on } s \text { and } \\
& \text { on } H(X) .
\end{aligned}
$$

Obviously, if the structure of cost or demand changes, so will $S$ and $s$.

14. This is demonstrated in the appendix mentioned above, available from the author. See also David Easley and Daniel F. Spulber, "Optimal Policies and Steady State Solutions for Inventory Problems with Markovian Uncertainty" (Brown University, January 1979).

15. In the Hadley-Whitin examples, firms that run out of stock retain unfilled orders for the next period, though there is a penalty cost for doing so. See Hadley and Whitin, Analysis of Inventory Systems, chap. 4, pp. 159-219. 
The system of equations in 7 implicitly defines the trigger points $S$ and $s$, and hence the width of the inventory range, as functions of the following parameters with the following derivatives:

$$
\begin{aligned}
& S=S\left(r, d, \frac{A}{c}, \frac{\delta}{c}, H(X)\right) \\
& s=s\left(r, d, \frac{A}{c}, \frac{\delta}{c}, H(X)\right) \\
& \text { - - + + } \\
& S-s=\sigma\left(r, d, \frac{A}{c}, \frac{\delta}{c}, H(X)\right) . \\
& -+?+
\end{aligned}
$$

These derivatives have straightforward interpretations. If either interest costs or storage costs rise, firms reduce both $S$ and $s$. But they change $S$ more, so the optimal lot size, $S-s$, falls. If the fixed cost of ordering rises relative to the marginal cost, firms reduce $s$ and increase the optimal lot size; the effects on $S$ are ambiguous. An increase in the penalty for running out of stock causes both $S$ and $s$ to move up, but the effect on the lot size is indeterminant. Finally, the derivative with respect to $H(X)$ is heuristic notation to indicate that if the density function of sales shifts to the right, that is, if sales increase, firms raise both $S$ and $s$ and increase the optimal lot size. All these results make good intuitive sense.

The empirical work reported in the next section is based on the notion that each of the exogenous variables listed in equation 8 influences the firm's choice of $S$ and $s$. The rate of interest, $r$, the manufacturer's price, $c$, and the distribution of sales, $H(X)$, are all captured by specific empirical variables. The fixed costs, $A$, and storage costs, $d$, are treated as unobservables.

\section{DYNAMIC ADJUSTMENTS BY A SINGLE FIRM}

Suppose now that a firm has selected its trigger points, $S$ and $s$. How will its inventories move through time? For simplicity, I assume that $S$ and $s$ are constant and an order placed within a period is received at the end of the period. 
Figure 1. Dynamic Adjustment of Inventories by a Single Firm ${ }^{\mathrm{a}}$

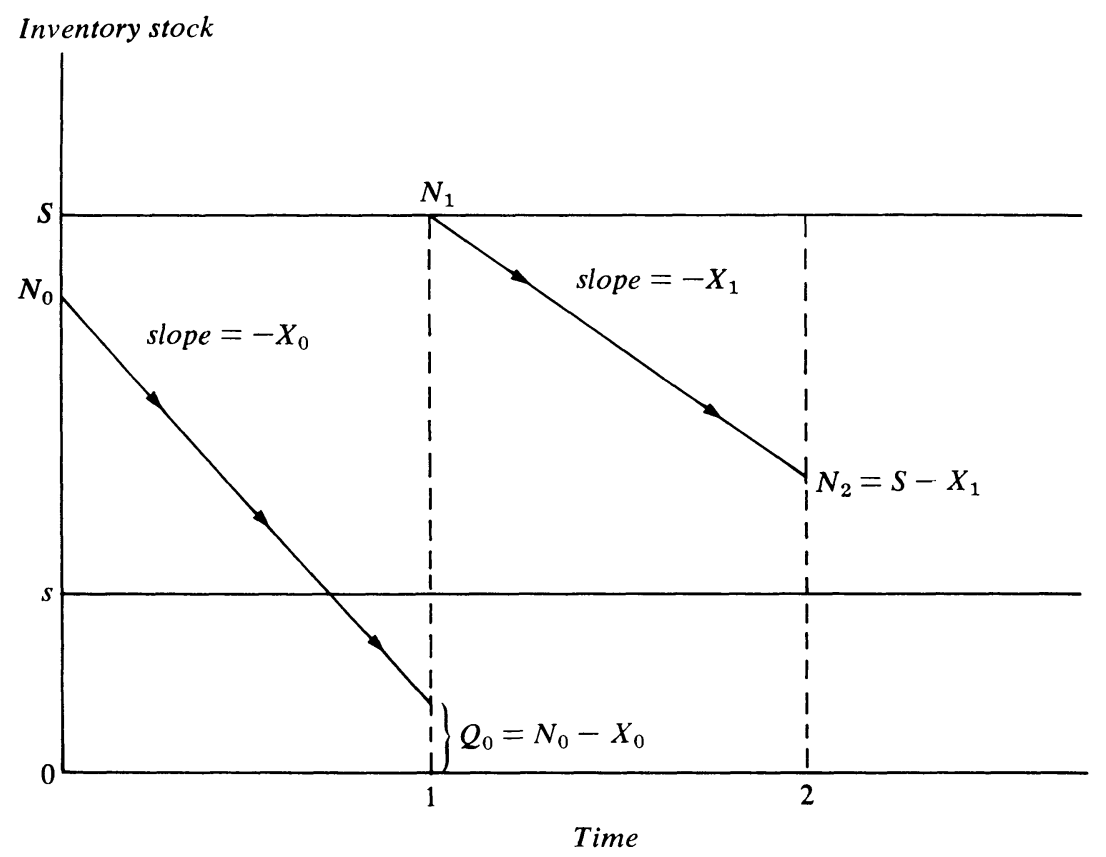

a. The variables $N, X$, and $Q$ denote real inventory stock, final sales, and carry-over stock, respectively.

Figure 1 traces the inventory holdings of a firm that starts with stock $N_{0}$ at time $t=0$, sells at the exogenously determined rate $X_{0}$ for the first week (between $t=0$ and $t=1$ ), and then sells at the rate $X_{1}$ for the second week (between $t=1$ and $t=2$ ).

Because inventories decline at the rate $X$ except at the points at which a firm receives delivery, the rate of sales, $X_{0}$, is shown as the slope of the line emanating from point $N_{0}$. In this example, inventories fall below $s$, the lower trigger point, during period 1 , so the firm places an order at the end of period 1 and a delivery is made replenishing the firm's stock so that it begins the next period with exactly $S$. Then inventories decline at rate $X_{1}$ until the end of the second week (point $N_{2}$ on the diagram).

Consider how this firm's behavior would differ if its sales in the second week were better than those assumed in figure 1, that is, suppose the line emanating from point $N_{1}$ were steeper. If it were only slightly steeper, $N_{2}$ 
would be lower than indicated in the figure. However, if it were substantially steeper, the firm would sell enough to justify placing an order during the second week, and so $N_{2}$ would end up at $S$. In general one cannot determine whether stronger sales lead to higher or lower end-of-period inventories. This is an interesting finding. It contrasts sharply with the stock-adjustment model in which it is always true that higher sales lead to lower end-of-period inventories. ${ }^{16}$ It also shows that firms that appear to be quite similarly situated might nonetheless exhibit divergent behavior patterns.

This example illustrates a general point: the $S, s$ model permits a far richer variety of dynamic behavior patterns than does the conventional stock-adjustment model. It may also help us to understand why inventory dynamics are so hard to predict.

\section{AGGREGATION ACROSS FIRMS}

If firms have a technology that makes the $S, s$ rule optimal, aggregation across firms is inherently difficult. ${ }^{17}$ Indeed, it is precisely this difficulty that has prevented the $S, s$ model from being used in empirical work to date. It is clear that the convenient fiction of the "representative firm" cannot be adopted because the essence of the $S, s$ rule is (1) that firms that are otherwise identical will react very differently to the same demand shock if they have different initial inventories, (2) that firms may react very differently to large demand shocks (which push inventories below $s$ ) than to small ones (which do not induce them to place an order), and (3) that $Y_{t}$ is not a continuous function of $X_{t}$ for a single firm. Hence one must be extremely careful about aggregation.

16. Strictly speaking, this statement is true only if $X_{t}$ is an independently and identically distributed random variable. If not, a rise in sales might lead the firm to increase its desired inventory level. However, the same is true of the $S, s$ model. If sales are serially correlated, "good" sales in the first week would lead the firm to raise $S$ and $s$ for the second week. Implicitly, figure 1 assumes that sales are independently and identically distributed.

17. George A. Akerlof has recently applied the $S, s$ model to aggregate money holdings in "Irving Fischer on His Head: The Consequences of Constant ThresholdTarget Monitoring of Money Holdings," Quarterly Journal of Economics, vol. 93 (May 1979), pp. 169-88. 
As a first step toward that aggregation, note that the $S, s$ rule in discrete time can be expressed as follows: ${ }^{18}$

$$
\begin{aligned}
& \text { If } N_{t}-X_{t}>s \text {, then } Y_{t}=0 . \\
& \text { If } N_{t}-X_{t} \leq s \text {, then } Y_{t}=S+X_{t}-N_{t} .
\end{aligned}
$$

It is convenient to introduce the variable $Q_{t}=N_{t}-X_{t}$. This variable, sometimes called the "carry-over stock" in the inventory literature, is the inventory stock the firm has at the end of the period if it does not receive a delivery at that time. ${ }^{19}$ Using this new variable, the $S, s$ rule can be expressed more succinctly as

$$
\text { If } Q_{t}>s \text {, then } Y_{t}=0 \text {; }
$$

$$
\text { if } Q_{t} \leq s \text {, then } Y_{t}=S-Q_{t}
$$

Now consider an industry in which there are a large number of small firms with the same costs and technology that face the same random distribution of demand shocks. All firms select the same $s$ and $S$ points. However, during any particular period, each firm inherits a different initial inventory stock, $N_{t}$, and receives a different drawing, $X_{t}$, from the (common) sales distribution. Hence the composite variable, $Q_{t}=N_{t}-X_{t}$, differs across firms according to some density function, which itself varies over time as initial inventory stocks change. I denote this function by $f_{t}\left(Q_{t}\right)$.

Using the notation $\bar{Y}_{t}$ to denote the average of $Y_{t}$ across firms, I average over the density of $Q_{t}$. Then the $S$, $s$ rule (equation 9) implies

$$
\bar{Y}_{t}=\int_{s-X_{1}}^{s}\left(S-Q_{t}\right) f_{t}\left(Q_{t}\right) d Q_{t},
$$

where $X_{1}$ is the largest possible realization of sales. Integrating this equation by parts and simplifying yields

$$
\bar{Y}_{t}=(S-s) F_{t}(s)+\int_{s-X_{1}}^{s} F_{t}\left(Q_{t}\right) d Q_{t},
$$

18. This formulation assumes either that $X_{t}$ is known at the start of period $t$ or that there are no delivery lags. If orders must be placed before sales are known, $Y_{t}$ can only depend on $X_{t}^{e}$, not on $X_{t}$.

19. See figure 1 for an example of $Q$. 
where $F_{t}\left(Q_{t}\right)$ is the cumulative distribution function corresponding to density $f_{t}\left(Q_{t}\right)$.

If mean sales are subtracted from both sides of 11 , one has an equation for inventory investment as a function of the distribution of sales, the distribution of initial inventories as captured in the distribution across firms of carry-over stock, and the parameters $S$ and $s$, which together indicate the desired inventory range. This inventory investment equation is quite different in spirit from the standard stock-adjustment specification. It is not only the means, but also the shapes, of the distributions of $X_{t}$ and $N_{t}$ that determine the mean of $Y_{t}$. For example, for any given distribution of sales and mean level of initial inventories, $\bar{Y}_{t}$ will be larger if the distribution of inventories has a concentration near $s$.

The dynamics inherent in 11 are easy to explain but difficult to analyze. The distribution of inventories at the start of each period, coupled with the distribution of sales for the same period, together induce some distribution of $Q_{t}$ for that period. Given $f_{t}\left(Q_{t}\right)$, mean deliveries for period $t$ follow directly from 11 and mean inventory investment is simply $\bar{Y}_{t}-\bar{X}_{t}$. The end-of-period inventory position of each firm is determined by the dynamics depicted in figure 1 . The distribution of closing inventories for period $t$ then becomes the distribution of opening inventories for period $t+1$, and the problem repeats.

\section{IMPLICATIONS AT THE INDUSTRY LEVEL}

Equation 11 is hardly suitable for econometric implementation as it stands. It is highly nonlinear and includes variables whose values cannot be observed. My estimation strategy is first to linearize the equation and then to introduce observable proxies for as many of the unobservable variables as possible. This subsection explains how the first step in this strategy is implemented. Most of the formal mathematics are relegated to appendix $\mathrm{A}$; the text illustrates the dynamics of the inventory behavior for a firm and for an aggregation of firms using a simple numerical simulation model that, although a special case, does a better job of conveying the nature of the results.

A Simulation Model. Consider an economy consisting of four firms with identical cost and demand structures, but whose ordering cycles are completely out of phase. Specifically, suppose each firm uses as trigger points $S=16$ and $s=2$ and, initially, sells four units every period. Table 
Table 5. Simulated Steady-State Inventory Cycle for a Single Firma

\begin{tabular}{cccccc}
\hline $\begin{array}{c}\text { Period, } \\
t\end{array}$ & $\begin{array}{c}\text { Initial } \\
\text { inventory, }\end{array}$ & $\begin{array}{c}\text { Sales, } \\
N_{t}\end{array}$ & $X_{t}$ & $\begin{array}{c}\text { Carry-over } \\
\text { stock, } \\
Q_{t}\end{array}$ & $\begin{array}{c}\text { Deliveries, } \\
Y_{t}\end{array}$ \\
\hline 0 & 16 & 4 & 12 & 0 & $\begin{array}{c}\text { Inventory } \\
\text { investment, } \\
N_{t+1}-N_{t}\end{array}$ \\
\hline 1 & 12 & 4 & 8 & 0 & -4 \\
2 & 8 & 4 & 4 & 0 & -4 \\
3 & 4 & 4 & 0 & 16 & -4 \\
4 & 16 & 4 & 12 & 0 & -4 \\
5 & 12 & 4 & 8 & 0 & -4 \\
6 & 8 & 4 & 4 & 0 & -4 \\
7 & 4 & 4 & 0 & 16 & 12 \\
b & & & & & \\
\hline
\end{tabular}

Source: Simulations by the author.

a. The trigger points are $S=16$ and $s=2$.

b. Cycle repeats in subsequent periods.

Table 6. Simulated Steady State for a Four-Firm Economy

\begin{tabular}{cccccc}
\hline $\begin{array}{c}\text { Period, } \\
t\end{array}$ & $\begin{array}{c}\text { Initial } \\
\text { inventory, } \\
N_{t}\end{array}$ & $\begin{array}{c}\text { Sales, } \\
X_{t}\end{array}$ & $\begin{array}{c}\text { Deliveries, } \\
Y_{t}\end{array}$ & $\begin{array}{c}\text { Inventory } \\
\text { investment, } \\
N_{t+1}-N_{t}\end{array}$ & $\begin{array}{c}\text { Inventory- } \\
\text { sales ratio }\end{array}$ \\
\hline 0 & 40 & 16 & 16 & 0 & 2.5 \\
1 & 40 & 16 & 16 & 0 & 2.5 \\
2 & 40 & 16 & 16 & 0 & 2.5 \\
3 & 40 & 16 & 16 & 0 & 2.5 \\
a & & & & &
\end{tabular}

Source: Simulations by the author.

a. All values are stable in subsequent periods.

5 shows the steady-state inventory cycle of one such firm; each of the others goes through the same ordering cycle, though with different timing. Say the economy consists of one firm that orders in periods $0,4,8, \ldots$; a second firm that orders in periods $1,5,9, \ldots$; a third that orders in periods $2,6,10, \ldots$; and a fourth ordering in periods $3,7,11, \ldots$ (as in table 5). The aggregate economy then exhibits the steady-state behavior summarized in table 6 . Inventory stocks are constant at 40 , and deliveries (which match sales) are 16 every period. Table 6 is an example of the steady state of equation 11 . In the paragraphs below, I consider how the system adjusts if it is subjected to a variety of different shocks.

Experiment 1: A Temporary Rise in Sales. Suppose there is a purely transitory sales fluctuation that does not induce firms to change their expectations about future sales or their target inventory range. Table 7 
Table 7. Effects of a Temporary Rise in Sales on a Single Firm

\begin{tabular}{|c|c|c|c|c|c|}
\hline $\begin{array}{c}\text { Period, } \\
t\end{array}$ & $\begin{array}{c}\text { Initial } \\
\text { inventory, } \\
N_{t}\end{array}$ & $\begin{array}{c}\text { Sales, } \\
X_{t}\end{array}$ & $\begin{array}{c}\text { Carry-over } \\
\text { stock, } \\
Q_{t}\end{array}$ & $\begin{array}{c}\text { Deliveries, } \\
Y_{t}\end{array}$ & $\begin{array}{c}\text { Inventory } \\
\text { investment, } \\
N_{t+1}-N_{t}\end{array}$ \\
\hline 0 & 16 & 6 & 10 & 0 & -6 \\
\hline 1 & 10 & 4 & 6 & 0 & -4 \\
\hline 2 & 6 & 4 & 2 & 14 & 10 \\
\hline 3 & 16 & 4 & 12 & 0 & -4 \\
\hline 4 & 12 & 4 & 8 & 0 & -4 \\
\hline 5 & 8 & 4 & 4 & 0 & -4 \\
\hline 6 & 4 & 4 & 0 & 16 & 12 \\
\hline 7 & 16 & 4 & 12 & 0 & -4 \\
\hline $\mathrm{a}$ & & & & & \\
\hline
\end{tabular}

Source: Simulations by the author.

a. Cycle repeats in subsequent periods.

shows the response of the firm in table 5 if sales are 6 in period 0 and then return to 4 thereafter. Inventories are drawn down more quickly than normal in period 0 , which induces the firm to place its next order in period 2 rather than period 3. Thereafter, it returns to its normal four-period cycle, but now its orders come in periods $2,6,10, \ldots$ instead of in periods 3,7 , $11, \ldots$. A one-time shock leaves a permanent imprint on the firm.

But different firms react differently to the same sales shock if they are at different stages in their replacement cycles. Indeed, a firm that is pushed below its trigger point will respond to this same shock by building up inventories in period 0 instead of drawing them down.

Table 8 shows what happens in the four-firm economy if all firms have sales of 6 in period 0 . Inventories accumulate at first, and the one-time shock converts the smooth behavior shown in table 6 into a rather unusual inventory cycle in which stocks decline from 44 to 28 every fourth period and then return to 44 . Similarly, both deliveries and inventory investment go through a four-period limit cycle. This is because the transitory shock created a degree of synchronization of orders among firms that was not present before.

Naturally, one does not expect the entire economy to behave this way forever. There are many reasons. Most obviously, shocks are not likely to be so perfectly correlated. Furthermore, prices would adjust to smooth the orders. For example, manufacturers would probably start posting higher prices in periods $4,8,12, \ldots$ when orders are 32 and lower prices in periods $3,7,11, \ldots$ when orders are zero so as to encourage some 
Table 8. Effects of a Temporary Rise in Sales on a Four-Firm Economy ${ }^{a}$

\begin{tabular}{|c|c|c|c|c|}
\hline $\begin{array}{c}\text { Period, } \\
\quad t\end{array}$ & $\begin{array}{c}\text { Initial } \\
\text { inventory, } \\
N_{t}\end{array}$ & $\begin{array}{c}\text { Sales, } \\
X_{t}\end{array}$ & $\begin{array}{c}\text { Deliveries, } \\
Y_{t}\end{array}$ & $\begin{array}{c}\text { Inventory } \\
\text { investment, } \\
N_{t+1}-N_{t}\end{array}$ \\
\hline 0 & 40 & 24 & 32 & 8 \\
\hline 1 & 48 & 16 & 14 & -2 \\
\hline 2 & 46 & 16 & 14 & -2 \\
\hline 3 & 44 & 16 & 0 & -16 \\
\hline 4 & 28 & 16 & 32 & 16 \\
\hline 5 & 44 & 16 & 16 & 0 \\
\hline 6 & 44 & 16 & 16 & 0 \\
\hline 7 & 44 & 16 & 0 & -16 \\
\hline 8 & 28 & 16 & 32 & 16 \\
\hline 9 & 44 & 16 & 16 & 0 \\
\hline 10 & 44 & 16 & 16 & 0 \\
\hline 11 & 44 & 16 & 0 & -16 \\
\hline b & & & & \\
\hline
\end{tabular}

Source: Simulations by the author.

a. All firms are assumed to have sales of 6 in period 0 .

b. Cycle repeats in subsequent periods.

retailers to adjust their ordering schedules. A simple way to avoid this artificial problem in the simulations is to assume that the economy consists of four sectors, each of which behaves exactly as shown in table 8, but that each is completely out of phase with the others. Sector A experiences the sales shock in period 0 , and hence behaves as in table 8 ; sector $\mathrm{B}$ experiences the shock in period 1 , and so lags behind by one period; and so on.

Table 9 shows the implied behavior of the four-sector (sixteen-firm) economy. In this more heavily populated economy a noncyclical steady state does reemerge beginning with period 6 . But note the interesting aggregative behavior. A four-period rise in sales induces inventory accumulation at first, followed by some rather abrupt inventory liquidation. This behavior-which is only one of a variety of possible patterns-is precisely the opposite of that predicted by the stock-adjustment model. In that model, a transitory and unexpected rise in sales leads to involuntary inventory decumulation followed by a gradual rebuilding of stocks.

Because this example is contrived, one should not try to draw general conclusions from it. In particular, it should not be concluded that transitory sales increases always lead to inventory accumulation. But the example does show that this outcome is quite possible and that the dynamics buried in equation 11 are both interesting and complex. 
Table 9. Effects of a Temporary Rise in Sales on a Four-Sector, Sixteen-Firm Economy

\begin{tabular}{cccccc}
\hline $\begin{array}{c}\text { Period, } \\
t\end{array}$ & $\begin{array}{c}\text { Initial } \\
\text { inventory, } \\
N_{t}\end{array}$ & $\begin{array}{c}\text { Sales, } \\
X_{t}\end{array}$ & $\begin{array}{c}\text { Deliveries, } \\
Y_{t}\end{array}$ & $\begin{array}{c}\text { Inventory } \\
\text { investment, } \\
N_{t+1}-N_{t}\end{array}$ & $\begin{array}{c}\text { inventory- } \\
\text { sales ratio }\end{array}$ \\
\hline 0 & 160 & 72 & 80 & 8 & 2.22 \\
1 & 168 & 72 & 78 & 6 & 2.33 \\
2 & 174 & 72 & 76 & 4 & 2.42 \\
3 & 178 & 72 & 60 & -12 & 2.47 \\
4 & 166 & 64 & 60 & -4 & 2.59 \\
5 & 162 & 64 & 62 & -2 & 2.53 \\
6 & 160 & 64 & 64 & 0 & 2.50 \\
7 & 160 & 64 & 64 & 0 & 2.50 \\
$b$ & & & & & \\
\hline
\end{tabular}

Source: Simulations by the author.

a. It is assumed that sector A experiences an increase in sales in period 0 , sector B in period 1 , and so on. b. All values are stable in subsequent periods.

To derive more general results about how the economy responds to a transitory sales shock, one must return to equation 11 and consider the effects of a shift parameter, $\gamma_{1}$, which denotes a uniform rightward shift of the density function of sales (an increase in sales). What effect would this have on average deliveries, $\bar{Y}_{t}$ ? The mathematics of this problem is presented in appendix $\mathrm{A}$; the answer is

$$
\frac{\partial \bar{Y}_{t}}{\partial \gamma_{1}}=(S-s) f(s)+F(s) \equiv 1+\theta>0 .
$$

This equation has a straightforward intuitive interpretation. The $F(s)$ indicates the number of firms placing an order in period $t$. If all firms experience a unit increase in sales, each of these firms raises its order by one unit. This accounts for the second term in 12 . The first term represents the firms that are just pushed below the $s$ trigger point by the increase in demand. There are $f(s)$ such firms, and they each order $S-s$. Equation 12 expresses the increase in aggregate orders as the sum of these two components.

The sign of $\theta$ is critical in what follows. For example, because aggregate inventory investment is $\bar{N}_{t+1}-\bar{N}_{t}=\bar{Y}_{t}-\bar{X}_{t}$, the effect of a transitory increase in mean sales on mean inventory investment is ${ }^{20}$

$$
\frac{\partial \Delta \bar{N}_{t}}{\partial \bar{X}_{t}}=\frac{\partial \bar{Y}_{t}}{\partial \bar{X}_{t}}-1=(1+\theta)-1=\theta
$$

20. Here and throughout the paper the symbol $\Delta N_{t}$ denotes $N_{t^{+1}}-N_{t}$. 
So whether inventories rise or fall depends on whether $\theta$ is positive or negative.

Figure 2 depicts two density functions, each with particular values of $S$ and $s$, corresponding respectively to cases in which $\theta>0$ and $\theta<0$. In each panel of the figure the area representing $(S-s) f(s)$ is shaded horizontally and the area representing $F(s)$ is shaded vertically. ${ }^{21}$ The sum of these two areas is $1+\theta$, and the area under the density function is 1.0. It is clear that the shape of the density function and the values of $S$ and $s$ are crucial to the value of $\theta$. In principle these are related since the distribution of carry-over stocks reflects the interaction of the distribution of sales and the $S, s$ policy, which itself depends on the distribution of sales.

In the top panel of figure 2 the density function of carry-over stocks, $f(Q)$, has a shape similar to a normal density and most firms have carryover stocks below $s$. It is clear that the areas labeled $F(s)$ and $(S-s) f(s)$ add up to more than the area under the density function. Thus $\theta$ is positive. Economically, this means that the additional orders from those firms that place orders overwhelm the declining stocks of the firms that do not place orders. Hence a rise in sales leads to an increase in average inventories.

The bottom panel of figure 2 shows the other case. Here the density function of $Q$ displays a strong negative skewness. The $S, s$ model makes such a shape quite plausible because it implies that the density function of initial inventories always has a mass of probability at $S$. In this panel $F(s)$ is rather small, and the horizontally shaded areas, $(S-s) f(s)$, are less than $1-F(s)$. Hence $\theta$ is negative.

Both cases are possible. All that is known on a priori grounds is that $\theta$ must exceed -1 because $1+\theta$ must be positive.

Notice also that $\theta$ need not be constant over time. Even if $S$ and $s$ are constant, the distribution function $F(Q)$ changes over time, reflecting fluctuations in sales, and hence so does $\theta$. In most of my empirical work, $\theta$ is treated as a constant; information on changes in the shape of the distribution of carry-over stocks is simply not available.

Finally, recall from the simulation model that the derivative (equation 12 ) is only the tip of the iceberg; it indicates the impact effect of a transitory sales shock. But such a shock sets in motion a complex dynamic

21. Since $X_{0}$ denotes the minimum possible value of sales, $S$ is necessarily larger than $S-X_{0}$ unless $X_{0}=0$. 
Figure 2. Distribution of Carry-over Stocks across Firms ${ }^{\mathrm{a}}$
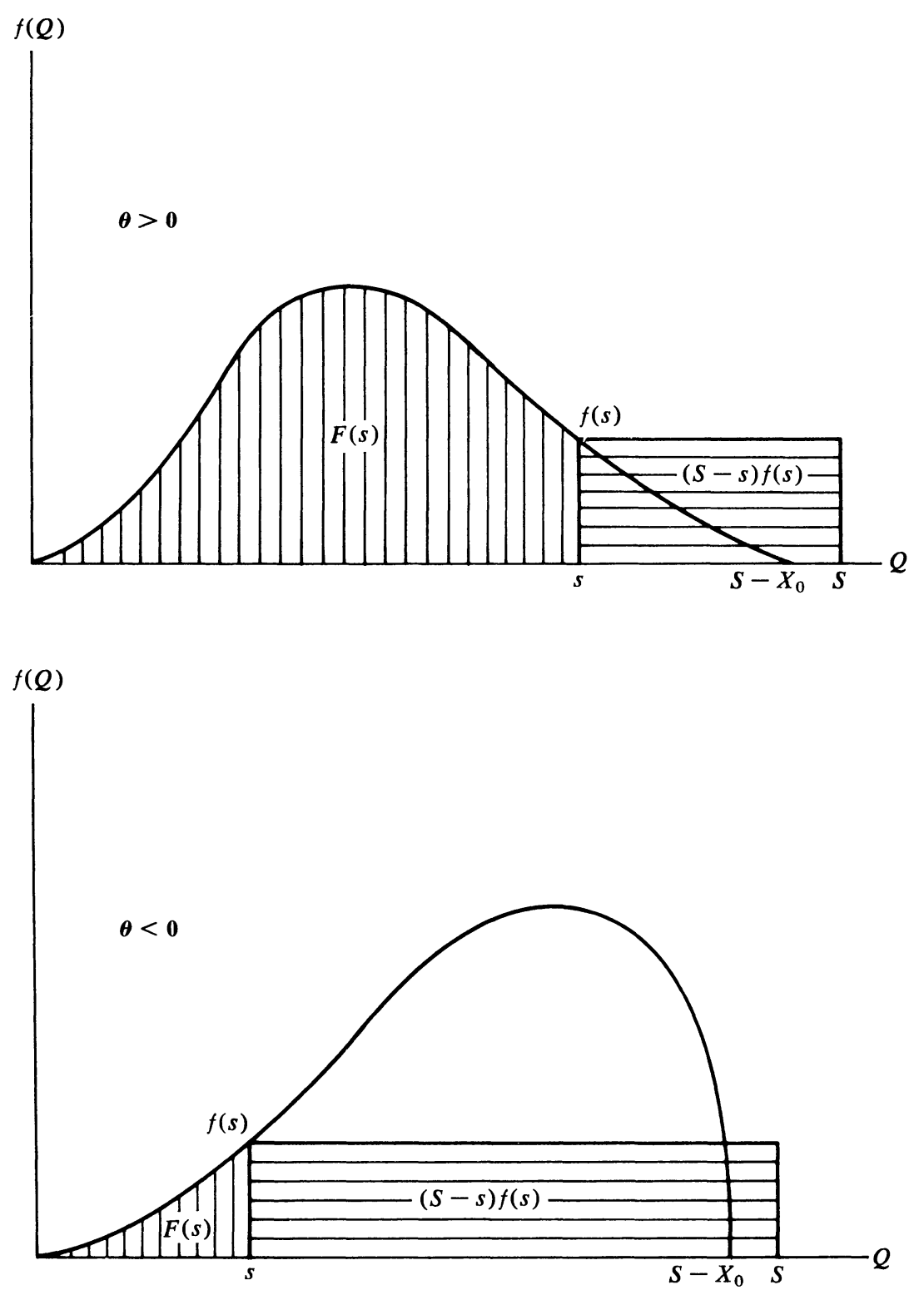

a. The $\theta$ is the effect of mean sales on mean inventory investment. The $Q$ is the carry-over stock. 
inventory adjustment process that may well be cyclical. This must be taken into account in the econometric formulation.

Experiment 2: A Rise in Initial Inventories. Consider what will happen if each firm discovers that it has some additional units in inventory and that nothing has happened to make it want to change either $S$ or $s$. Empirically this is meant to capture the firm's reactions to above-average inventories that arise from mistakes or are the legacy of a past sales shock that triggered an order. (For example, in experiment 1, firms accumulated inventories for a while and then liquidated stocks.)

Because the critical variable for the firm is $Q=N-X$, a positive shock to $N$ is just like a negative shock to $X$-the case just analyzed. Thus, if the shift parameter $\gamma_{2}$ is used to connote a uniform rightward shift of the density function of inventories, it follows immediately that

$$
\frac{\partial \bar{Y}_{t}}{\partial \gamma_{2}}=-(1+\theta)<0
$$

In words, excess inventories always reduce orders.

Experiment 3: A Shift in the $S$, $s$ Range. Thus far I have not considered what happens if the firm decides to change its $S$ or $s$. But, as mentioned above, changes in a variety of exogenous variables could make the firm want to change its trigger points. Suppose, first, that the entire $S, s$ range shifts upward, with no change in $(S-s)$ and no change in the distributions of either initial inventories or sales. (For example, I suggested above that a rise in $\delta$, the penalty cost of back ordering, might have this effect.) Clearly, such a change will make inventories too low on average and induce firms to accumulate inventories, thus changing the distributions of inventories and carry-over stocks in the future. But what will the adjustment pattern be?

Table 10 shows the behavior of the same firm that was depicted in table 5 on the assumption that both $S$ and $s$ rise by two units, to $S=18$ and $s=4$, in period 0 . Instead of waiting until period 3 and ordering sixteen units, the firm now places an order in period 2 but orders only fourteen units. Other firms react differently because the change in $S$ and $s$ happens at different points in their ordering cycles. The behavior of the four-firm sector (not shown here) once again displays a rather unusual steady-state inventory cycle. 
Table 10. Effects of a Rise in $S$ and $s$ on a Single Firm ${ }^{a}$

\begin{tabular}{cccccc}
\hline $\begin{array}{c}\text { Period, } \\
t\end{array}$ & $\begin{array}{c}\text { Initial } \\
\text { inventory, } \\
N_{t}\end{array}$ & $\begin{array}{c}\text { Sales, } \\
X_{t}\end{array}$ & $\begin{array}{c}\text { Carry-over } \\
\text { stock, } \\
Q_{t}\end{array}$ & $\begin{array}{c}\text { Deliveries, } \\
Y_{t}\end{array}$ & $\begin{array}{c}\text { Inventory } \\
\text { investment, } \\
N_{t+1}-N_{t}\end{array}$ \\
\hline 0 & 16 & 4 & 12 & 0 & -4 \\
1 & 12 & 4 & 8 & 0 & -4 \\
2 & 8 & 4 & 4 & 14 & 10 \\
3 & 18 & 4 & 14 & 0 & -4 \\
4 & 14 & 4 & 10 & 0 & -4 \\
5 & 10 & 4 & 6 & 0 & -4 \\
6 & 6 & 4 & 2 & 16 & 12 \\
7 & 18 & 4 & 14 & 0 & -4 \\
$\mathrm{~b}$ & & & & & \\
\hline
\end{tabular}

Source: Simulations by the author.

a. The rise is two units, to $S=18$ and $s=4$, in period 0 .

b. Cycle repeats in subsequent periods.

Table 11. Effects of a Rise in $S$ and $s$ on a Four-Sector, Sixteen-Firm Economy ${ }^{\text {a }}$

\begin{tabular}{cccccc}
\hline $\begin{array}{c}\text { Period, } \\
t\end{array}$ & $\begin{array}{c}\text { Initial } \\
\text { inventory, } \\
N_{t}\end{array}$ & $\begin{array}{c}\text { Sales, } \\
X_{t}\end{array}$ & $\begin{array}{c}\text { Deliveries, } \\
Y_{t}\end{array}$ & $\begin{array}{c}\text { Inventory } \\
\text { investment, } \\
N_{t+1}-N_{t}\end{array}$ & $\begin{array}{c}\text { inventory- } \\
\text { sales ratio }\end{array}$ \\
\hline 0 & 160 & 64 & 80 & 16 & 2.50 \\
1 & 176 & 64 & 78 & 14 & 2.75 \\
2 & 190 & 64 & 76 & 12 & 2.97 \\
3 & 202 & 64 & 60 & -4 & 3.16 \\
4 & 198 & 64 & 60 & -4 & 3.09 \\
5 & 194 & 64 & 62 & -2 & 3.03 \\
6 & 192 & 64 & 64 & 0 & 3.00 \\
7 & 192 & 64 & 64 & 0 & 3.00 \\
$\mathrm{~b}$ & & & & &
\end{tabular}

Source: Simulations by the author.

a. Sector A is assumed to raise $S$ and $s$ in period 0 , sector B in period 1 , and so on.

b. All values are stable in subsequent periods.

Table 11 takes the next step and analyzes the behavior of four such sectors. One sector raises $S$ and $s$ in period 0; another sector raises $S$ and $s$ in period 1; and so on. Here the jagged edges are smoothed out, and a clear pattern emerges that resembles overshooting. Such overshooting in response to a rise in desired inventories can never occur in a stock-adjustment model. But table 11 shows that it can occur in an $S, s$ model even though no firm ever allows its inventories to exceed $S$.

More formally, if shift parameter $\gamma_{3}$ denotes a change in an exogenous 
variable that moves $S$ and $s$ equally, and does not change $F(Q)$, equation 11 implies

$$
\frac{\partial \bar{Y}_{t}}{\partial \gamma_{3}}=1+\theta>0
$$

This derivative is equal and opposite to equation 13, which makes sense. If, for some reason, $\bar{N}_{t}, S$, and $s$ all increase equally at the same time, there will be no effect on $\bar{Y}_{t}$.

Experiment 4: A Widening of the $S$, s Range. Not all changes in the firm's price and cost structure will induce it to move $S$ and $s$ equally. For example, as mentioned, an increase in the fixed cost of purchasing, $A$, would raise $S-s$, lower $s$, and have an unclear effect on $S$. So it is worth exploring what happens if either $s$ or $S$, but not both, changes. Let $\gamma_{4}$ denote a change in some parameter that moves $S$ but leaves $s$ unchanged. Then, by equation 11 ,

$$
\frac{\partial \bar{Y}}{\partial \gamma_{4}}=F(s)>0
$$

Alternatively, if $\gamma_{4}^{\prime}$ denotes a change in some parameter that moves $s$ but leaves $S$ unchanged, then

$$
\frac{\partial \bar{Y}}{\partial \gamma_{4}^{\prime}}=(S-s) f(s)>0
$$

Either sort of shift raises inventory investment initially, and then has subsequent effects by changing the distribution of carry-over stocks in future periods.

Clearly, among the three shift parameters $-\gamma_{3}, \gamma_{4}$, and $\gamma_{4}^{\prime}$-one is redundant because $\gamma_{3}$ is just the sum of $\gamma_{4}$ and $\gamma_{4}^{\prime}$. In what follows I work with $\gamma_{3}$-which represents equal changes in both $S$ and $s$ and with $\gamma_{4}$ which represents a rise in $S$ and $s$ fixed.

Experiment 5: An Anticipated Rise in Sales. Now I come to the source of variation in deliveries that $\mathrm{I}$ believe is predominant in the data actually observed. Suppose that most sales fluctuations experienced by retailers are anticipated, so that a higher $X_{t}$ is preceded by a higher $S$, $s$, or both. In this case, each rightward shift of the distribution of sales (as in experiment 1 ) is accompanied by a rightward shift in the distribution of initial 
inventories (as in experiment 2). ${ }^{22}$ Hence the effects of an expected, and presumably persistent, increase in sales can be captured by combining the experiments conducted above. Specifically, the shift parameter denoting an anticipated rise in sales, $\gamma_{5}$, is composed of the following combination of shift parameters already discussed: a one-unit rise in $\gamma_{1}$ (an increase in sales), a $b$ unit increase in $\gamma_{2}$ (an increase in initial inventories), either an $a_{1}$ unit increase in $\gamma_{4}$ (a widening of the $S$, $s$ range) or an $a_{2}$ unit increase in $\gamma_{3}$ (an upward shift of the $S, s$ range).

The new parameters introduced here have fairly clear intuitive meanings. The parameters $a_{1}$ and $a_{2}$ are like marginal inventory sales ratios; they represent the sensitivity of desired inventories to expected sales. The derivatives in equation 8 , which are for a specific example, lead one to expect $S$, $s$, or both to respond positively to anticipated sales. Notice that this presumption does not quite follow from the mathematics. Hadley and Whitin derive equation 7 for a firm whose sales each period are drawn from an unchanged probability distribution. The derivatives in equation 8 thus compare different firms with different but stationary sales distributions. I use these results to predict the response of a firm that anticipates a change in its own sales distribution for the next period. For this reason, I imagine that, in addition to the factors enumerated in 7 , the parameters $a_{1}$ and $a_{2}$ depend in an important way on how persistent, and hence how predictable, demand fluctuations are. More persistent fluctuations, I surmise, lead to higher values of $a_{1}$ or $a_{2}$.

The parameter $b$, which measures the responsiveness of initial inventories, $N_{t}$, to expected sales, $X_{t}^{e}$, should depend on all the factors that influence $a_{1}$ or $a_{2}$ and in addition on the degree of uncertainty firms attach to the forecasts and on how risk averse they are.

In what follows I deal with two different models, corresponding to two different ways in which the $S, s$ range may be affected. In model 1 , changes in the target inventory range are assumed to take the form of equal movements in $S$ and $s$. So the effect of shift parameter $\gamma_{5}$ on mean orders is

$$
\frac{\partial \bar{Y}}{\partial \gamma_{5}}=\frac{\partial \bar{Y}}{\partial \bar{X}^{e}}=1+\theta-b(1+\theta)+a_{2}(1+\theta)=\left(1-b+a_{2}\right)(1+\theta),
$$

22. The firms that do place orders will have a higher $S_{t}$ and will thus place larger orders, resulting in higher initial inventories the following period. If firms adjust $s_{t}$ upward, more firms find themselves tripping the lower barrier and hence placing orders. 
where the $1+\theta$ term comes from the shift in the distribution of sales; the $b(1+\theta)$ term comes from the shift in the distribution of initial inventories; and the $a_{2}(1+\theta)$ term comes from the shift in $S$ and $s$. In model 0 , shocks to desired inventory holdings are assumed to correspond to changes in $S$ with $s$ fixed, widening or narrowing the $S, s$ range. Thus the effect of the composite shift parameter $\gamma_{5}$ is

$$
\frac{\partial \bar{Y}}{\partial \gamma_{5}}=\frac{\partial \bar{Y}}{\partial \bar{X}^{e}}=1+\theta-b(1+\theta)+a_{1} F(s)=(1-b)(1+\theta)+a_{1} F(s),
$$

where the sales and initial inventory terms are the same as in model 1 and the $a_{1} F(s)$ term comes from the shift in $S$. To economize on notation, I introduce the parameter $\lambda$, which takes on the value $\lambda=1$ for model 1 and $\lambda=0$ for model 0 , and write the two expressions more succinctly as

$$
\frac{\partial \bar{Y}}{\partial \gamma_{5}}=\frac{\partial \bar{Y}}{\partial \bar{X}^{e}}=(1+\theta)(1-b)+\lambda a_{2}(1+\theta)+(1-\lambda) a_{1} F(s) \equiv K_{1}
$$

Experiment 6: An Unanticipated Rise in Sales. There is one other type of composite shock that appears to have empirical relevance: a change in the mean of the sales distribution that was not anticipated. By definition, an unanticipated sales shock cannot affect beginning-of-period inventories. However, as long as the random process generating sales is not independently and identically distributed, sales shocks contain information relevant to predicting future sales and hence induce firms to alter their $S, s$ target range. Hence I consider an unanticipated rise in sales, $X_{t}^{u}$, to be a composite of a unit increase in $\gamma_{1}$ (a rise in sales) and either an $a_{3}$ unit increase in $\gamma_{4}$ (a rise in $S$ alone) in model 0 or an $a_{4}$ unit increase in $\gamma_{3}$ (a rise in both $S$ and $s$ ) in model 1.

So, if one denotes the shift parameter representing an unanticipated sales shock $\gamma_{6}$ and once again uses the convenient variable $\lambda$ to capture both models in a single expression, the following relation is implied:

$$
\frac{\partial \bar{Y}}{\partial \gamma_{6}}=\frac{\partial \bar{Y}}{\partial \bar{X}^{u}}=1+\theta+\lambda a_{4}(1+\theta)+(1-\lambda) a_{3} F(s) \equiv K_{2}
$$

where the $\lambda a_{4}(1+\theta)+(1-\lambda) a_{3} F(s)$ terms come from the appropriate changes in the $S, s$ range. Note that $K_{2}$, which is the effect of a unit increase 
in $\bar{X}_{t}^{u}$ on mean deliveries, may be greater than or less than $K_{1}$, which is the effect of a unit increase in $\bar{X}_{t}^{e}$. In versions of the $S, s$ models in which delivery lags are unimportant, there is no particular implication about whether expected or unexpected sales should have the stronger effect on inventory investment. This, once again, stands in sharp contrast to the stock-adjustment model.

As pointed out above, equations like 16 and 17 indicate only the impact effects of increases in sales, but there are also complicated dynamic adjustments inherent in 11 . These dynamics need to be captured in the econometric specification.

\section{Empirical Implementation of the $S$, $s$ Model}

To create regression equations from this analysis it is necessary to relate the theoretical shift parameters to empirical variables. One must also assume that parameters like $K_{1}$ and $K_{2}$, which in principle vary, are constant through time. It will be easiest first to write down the twoequation empirical model that is meant to represent the theoretical model and then to explain it by components. Thus

$$
\begin{aligned}
& Y_{t}=K_{1} X_{t}^{e}+K_{2} X_{t}^{u}+K_{3}\left(\eta_{t+1}-\eta_{t}\right)-(1+\theta) u_{t}+\epsilon_{t} \\
& N_{t}=b X_{t}^{e}+\eta_{t}+u_{t} .
\end{aligned}
$$

The first term on the right-hand side of each equation represents the effects of anticipated increases in sales. According to experiment 5, a unit increase in $X_{t}^{e}$ raises $Y_{t}$ by an amount $K_{1}$ and raises $N_{t}$ by $b$.

Experiment 6 is interpreted as an unexpected increase in sales, $X_{t}^{u}$. It was shown that a unit increase in $X_{t}^{u}$ moves $Y_{t}$ by $K_{2}$ units, but does not affect $N_{t}$. This is reflected in equations 18 and 19.

The variable $\eta_{t}$ represents exogenous variables other than $X_{t}^{e}$ and $X_{t}^{u}$ that influence $S$ and $s$. As has been shown above in an explicit example, interest rates, manufacturer's prices, and fixed costs are among these variables.

A concrete example may help clarify the nature of $\eta$. One of the determinants of $S$ and $s$ is the fixed cost of making a purchase. An increase 
in $A$ is expected to widen the $S, s$ range. Suppose this happens by raising $S$ with $s$ fixed. ${ }^{23}$ Let $\omega$ denote the derivative $d S / d A$. Then, according to experiment 3, an increase in $A$ by $1 / \omega$ units would push $S$ up by one unit and raise $Y_{t}$ by $1+\theta$ units. Hence, if $A$ were the only factor determining $S$ and $s$, one would simply define $\eta$ as $A / \omega$. Other variables that influence $S$ and $s$, such as interest rates and storage costs, can be handled similarly. In the empirical work, $\eta_{t}$ is actually a vector of variables. The units of measurement for the elements of $\eta$ are chosen to make unity the coefficient of $\eta_{t}$ in equation 19. Variable $\eta_{t}$ is dated so that $\eta_{t}$ captures the influences on beginning-of-period inventories and $\eta_{t+1}-\eta_{t}$ captures the change in these influences during the period. The model therefore implies that a unit increase of $\eta$ raises $Y_{t}$ by $(1+\theta)$ units in model 1 (equal increases in $S$ and $s$ ) or by $F(s)$ units in model 0 (a rise in $S$ alone). Once again I can economize on notation by defining the coefficient of $\eta_{t+1}-\eta_{t}$ in equation 18 as

$$
K_{3}=\lambda(1+\theta)+(1-\lambda) F(s) \equiv F(s)+\lambda(S-s) f(s),
$$

which encompasses both models.

The most difficult variable to explain in equations 18 and 19 is $u_{t}$, which is something akin to undesired inventories. But that description is not really accurate because the micro model implies that firms only have a desired inventory range, not level, and that they always keep inventories within this range. The best way to understand $u_{t}$ is to recall the complicated dynamic adjustments in the simulation model. After a shock there is always a period that has the earmarks of inventory disequilibrium, even though each individual firm always has its inventories where it wants them, given its past history and its $S, s$ trigger points. This disequilibrium is particularly clear, for example, in table 11 in which there appears to be overshooting following a rise in $S$ and $s$. The variable $u_{t}$ in equations 18 and 19 is meant to embody the legacy of all past shocks and errors; it is the way these apparently simple equations accommodate the complex dynamics of the $S$, $s$ model. ${ }^{24}$

Equation 19 amounts to a definition of $u_{t}$. The terms $b X_{t}^{e}+\eta_{t}$ can be

23. In fact, in the example given above for firms that have exogenous sales and minimize long-run costs in a stationary environment, the widened range is accompanied by a reduction in $s$.

24. The evolution of $u_{t}$ through time is governed by a difference equation that is derived in appendix $B$. 
thought of as the steady-state level of average inventories-corresponding, for example, to the entry 192 in table 11 . Then $u_{t}$ measures the deviation of actual inventories from this steady state, period by period. To decide on the proper coefficient for $u_{t}$ in equation 18 , one must connect it with one of the experiments in the previous section. The most natural one seems to be experiment 2 , which deals with a shift of the distribution of $N_{t}$ when all the determinants of $S$ and $s$ are held constant. Hence the coefficient $-(1+\theta)$ is assigned to $u_{t}$ in equation 18 .

Plainly, there are no data on $u_{t}$ to permit estimation of 18 and 19 directly. There are two routes that can be followed in deriving an estimating equation. The most obvious, but I will argue inappropriate, procedure is to solve 19 for $u_{t}$ and substitute into 18 to obtain

$$
\begin{aligned}
Y_{t}= & {\left[(1+\theta)(1-b)+a_{1} F(s)\right] X_{t}^{e}+\left[1+\theta+a_{3} F(s)\right] X_{t}^{u} } \\
& -(1+\theta) N_{t}+(1+\theta) \eta_{t}+F(s)\left[\eta_{t+1}-\eta_{t}\right]+\epsilon_{t}
\end{aligned}
$$

in model $0(\lambda=0)$, or

$$
\begin{aligned}
Y_{t}= & \left(1+a_{2}\right)(1+\theta) X_{t}^{e}+\left(1+a_{4}\right)(1+\theta) X_{t}^{u} \\
& -(1+\theta) N_{t}+(1+\theta) \eta_{t+1}+\epsilon_{t}
\end{aligned}
$$

in model $1(\lambda=0)$. These equations, which may look complicated, are actually rather conventional. If one treats $\eta_{t}$ as a stochastic disturbance, either 20 or 21 can be written as

$$
Y_{t}=A_{1} X_{t}^{e}+A_{2} X_{t}^{u}+B N_{t}+\text { error }
$$

with suitable interpretations of $A_{1}, A_{2}$, and $B$. This is exactly the econometric specification normally used to represent the stock-adjustment model (compare equation 5). The only difference is that the parameters have very different interpretations.

However, there is a problem with the error terms in 20 and 21. It is most obvious in 20, in which $\eta_{t}$ is part of the error term, while 19 implies that $N_{t}$ and $\eta_{t}$ have a positive covariance. Thus the coefficient of $N_{t}$ in 20 should be biased. The same problem arises in 21 if $\eta_{t}$ is serially cor- 
related. There can be little doubt that it is. In the empirical work, $\eta_{t}$ is represented by

$$
\eta_{t}=\alpha R_{t}+v_{t}
$$

where $R_{t}$ is a vector of measurable variables that influence $S$ and $s$ such as interest rates and manufacturers' prices, and $v_{t}$ is the truly unobservable component. Thus $v_{t}$ reflects, among other things, changes in the cost technology (storage costs and the ratio $A / c$ ), changes that one expects to be persistent and perhaps even permanent-that is, $v_{t}$ may well be a random walk.

A better way of deriving an estimating equation is found by using the model to eliminate $u_{t}$ from equation 18 . This is done in appendix $\mathrm{B}$; there it is shown that the model can be reformulated as

$$
\begin{aligned}
\Delta N_{t}= & -\theta \Delta N_{t-1}+\left[\theta+a_{1} F(s)\right]\left(X_{t}^{e}-X_{t-1}^{e}\right) \\
& +\left[\theta+a_{3} F(s)\right]\left(X_{t}^{u}-X_{t-1}^{u}\right)+(1+\theta) z_{t-1} \\
& +F(s)\left[z_{t}-z_{t-1}\right]+\epsilon_{t}-\epsilon_{t-1}
\end{aligned}
$$

in model $0(\lambda=0)$, or

$$
\begin{aligned}
\Delta N_{t}= & -\theta \Delta N_{t-1}+\left[\theta+a_{2}(1+\theta)\right]\left(X_{t}^{e}-X_{t-1}^{e}\right) \\
& +\left[\theta+a_{4}(1+\theta)\right]\left(X_{t}^{u}-X_{t-1}^{u}\right)+(1+\theta) z_{t} \\
& +\epsilon_{t}-\epsilon_{t-1}
\end{aligned}
$$

in model $1(\lambda=1)$, where I introduce the new symbol, $z_{t}$, as shorthand for $\eta_{t+1}-\eta_{t}$.

Equation 24 has some chance of being a legitimate equation for estimation. The econometric error term in this equation is

$$
(1+\theta)\left(v_{t+1}-v_{t}\right)+\left(\epsilon_{t}-\epsilon_{t-1}\right) .
$$

The first term is assumed to be uncorrelated with all the variables in the equation, and will be almost independently and identically distributed if $v_{t}$ is close to a random walk, which is a plausible case. The second term will also be uncorrelated with all the variables in the model. But it will be highly serially correlated if $\epsilon_{t}$ is serially independent. On the other hand, 
if $\epsilon_{t}$ is approximately a random walk, $\epsilon_{t}-\epsilon_{t-1}$ will be approximately "white noise."

The error term in 23 potentially has a rather complicated serial correlation structure, even if one is willing to assume that $v_{t}$ is a random walk. However, it will still be orthogonal to all the variables in the equation. Thus estimation of 23 and 24 by ordinary least squares seems likely to give unbiased coefficient estimates, even if they are inefficient.

To make 23 or 24 operational, it is only necessary to specify the variables in the vector $R_{t}$ (see equation 22) and to obtain a time series on expected sales. The latter is explained below. For the former, I have tried interest rates and the ratio of manufacturers' prices, $c_{t}$, to retail prices, $p_{t}$.

\section{The Data}

Because a firm's optimal choices of $S$ and $s$ are sensitive to its cost and demand structures, firms in different industries are expected to make quite different choices of $S$ and $s$ and of the parameters $a_{1}$ through $a_{4}$ above. Thus I decided to work at a level that was as disaggregated as the data permitted. In practice, this meant dividing retailing into eight subsectors. In addition, results are reported for all retailing. However, as shown below, automobiles dominate the results for all retailing.

\section{SALES AND INVENTORIES}

The basic data on the sales and inventories of retailers are unpublished and have only recently become available. The data are monthly and seasonally adjusted, covering the period from January 1959 through December $1980 .{ }^{25}$ Both sales and inventories are deflated by the U.S. Bureau of Economic Analysis and are expressed in 1972 prices at monthly rates. ${ }^{26}$

A word on the overall trend in these data is in order. In the period before the first OPEC shock, inventories in most sectors were growing faster than sales. Despite all the talk about improved inventory control

25. In principle, seasonally unadjusted data would have been preferable, but these are not available in real terms.

26. The deflation procedure for inventories is a complex one using, among other things, information on LIFO (last in, first out) versus FIFO (first in, first out) accounting procedures. The documentation by the U.S. Bureau of Economic Analysis explaining the procedures in detail is still in preparation. 


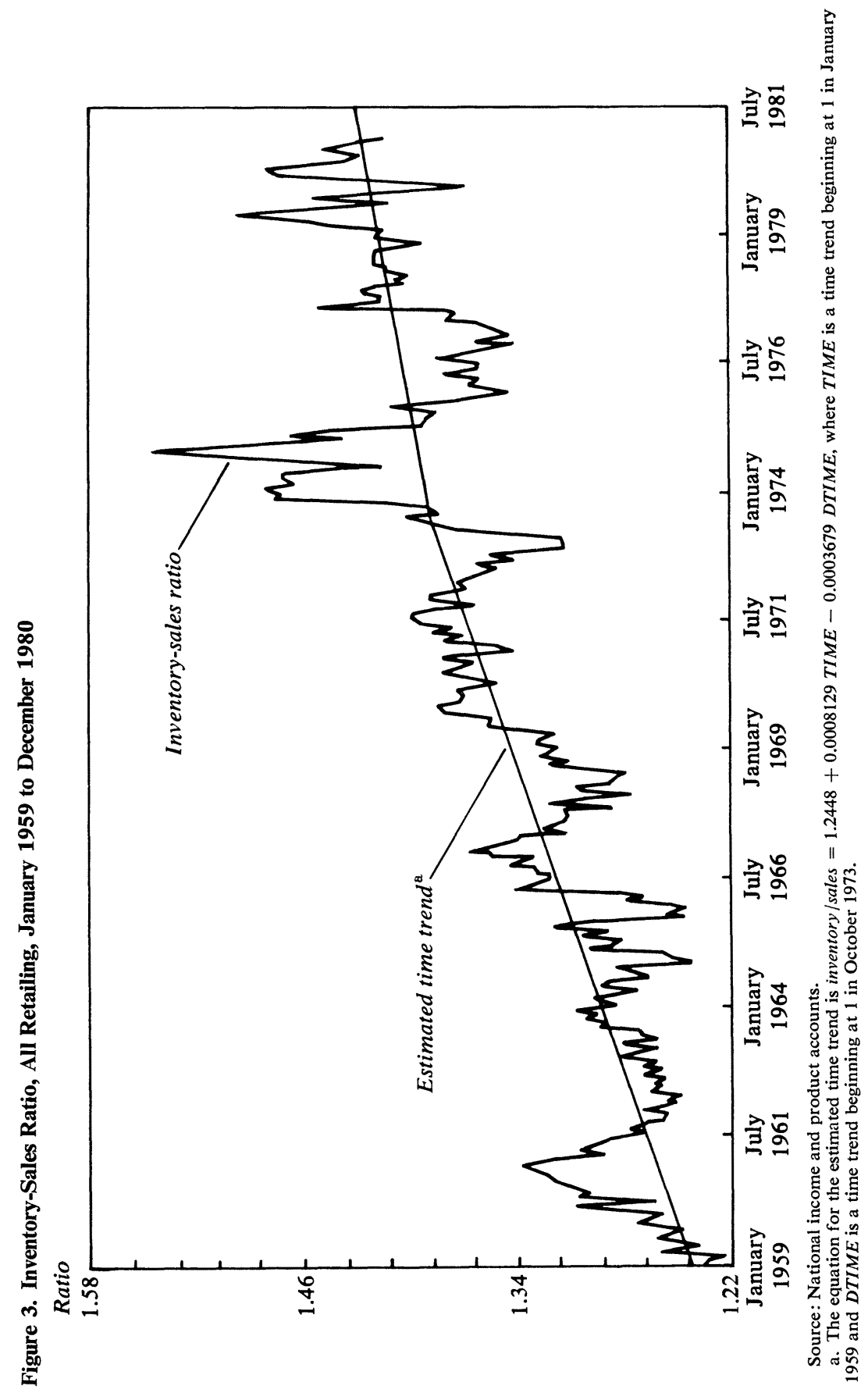


Table 12. Descriptive Statistics on Sales and Inventory Data, by Sector, January 1959 to December 1980

\begin{tabular}{|c|c|c|c|c|c|}
\hline \multirow[b]{3}{*}{ Sector } & \multirow{2}{*}{\multicolumn{2}{|c|}{ Sales }} & \multicolumn{3}{|c|}{ Inventories } \\
\hline & & & \multirow[b]{2}{*}{$\begin{array}{c}\text { Mean } \\
\text { inventory } \\
\text { stock }^{\mathrm{c}}\end{array}$} & \multirow{2}{*}{$\begin{array}{c}\text { Variance of } \\
\text { inventory } \\
\text { investment } \\
\text { about } \\
\text { trend }\end{array}$} & \multirow{2}{*}{$\begin{array}{l}\text { Mean- } \\
\text { inventory } \\
\text { sales } \\
\text { ratio }\end{array}$} \\
\hline & $M_{e a n^{\mathrm{a}}}$ & $\begin{array}{c}\text { Variance } \\
\text { about } \\
\text { trend }^{\mathrm{b}}\end{array}$ & & & \\
\hline All retailing & 34.20 & 1.3200 & 46.50 & 0.1338 & 1.34 \\
\hline \multicolumn{6}{|l|}{ Durables } \\
\hline Automobiles & 6.45 & 0.3320 & 10.14 & 0.0741 & 1.53 \\
\hline Furniture and appliances & 1.66 & 0.0067 & 3.58 & 0.0016 & 2.12 \\
\hline Lumber and hardware & 1.75 & 0.0208 & 3.83 & 0.0013 & 2.22 \\
\hline Other durables & 1.16 & 0.0169 & 3.22 & 0.0033 & 2.83 \\
\hline \multicolumn{6}{|l|}{ Nondurables } \\
\hline Food & 7.69 & 0.0439 & 5.39 & 0.0028 & 0.70 \\
\hline Apparel & 2.02 & 0.0076 & 4.80 & 0.0030 & 2.39 \\
\hline General merchandise & 4.88 & 0.0405 & 8.89 & 0.0191 & 1.80 \\
\hline Other nondurables & 8.59 & 0.0436 & 6.69 & 0.0062 & 0.78 \\
\hline
\end{tabular}

and economies of scale in inventories, the inventory-sales ratio was generally increasing in retailing. (See figure 3 , which pertains to all retailing.) This basic fact is sometimes read as evidence against the $S, s$ model because the square root rule is thought to suggest that inventories should grow as the square root of sales. There is no contradiction, however. For example, if economic growth is characterized mainly by more firms or by firms expanding the number of products they handle rather than by firms with fixed product lines growing larger, the square root rule would not be relevant to the trend movement in inventories.

Table 12 offers some descriptive statistics on these data, intended to give an idea of the relative sizes of the various sectors and how much of the overall variance comes from each sector. It can be seen that there are only two large sectors in terms of inventory holding: automobile dealers and general merchandise stores (primarily department stores). It can also be seen that the sectors vary widely in how much inventory they hold relative to sales. The inventory-sales ratio is highest in the apparel and other durables categories, lowest in food and other nondurables. The range of time is impressive: from 21 days to 85 days of sales. 
When one looks at variances in the detrended data, the real dominance of the automobile sector is revealed. The variance around trend of automobile sales is $7 \frac{1}{2}$ times larger than that of the next largest sector, and in fact far exceeds the sum of the variances of all other sectors. In terms of inventory investment, the dominance of the automobile industry is even more complete. Except for general merchandise, the variance about trend of automobile inventory investment is at least twelve times greater than that in any other sector. In a word, cyclical inventory variability is essentially a matter of automobile dealer and department store behavior.

It is thus worth considering the a priori plausibility of the $S, s$ model for automobile dealers and department stores. Department stores appear to be an industry in which the $S, s$ rule should apply well. Deliveries presumably come in by the truckload, whereas sales are made continuously. The automobile industry presents a less obvious case. A truckload of automobiles is not a very large number, which suggests that the lot size, $S-s$, may be quite small relative to monthly sales for a typical dealer. This diminishes the importance of the $S, s$ rule. The need to have a variety of models on display and ready for immediate delivery may be a more important factor in explaining the size of automobile inventories. Furthermore, the distinction between manufacturers' inventories of finished goods and retail inventories is a slippery one in this industry. While dealers are generally independent, and quite competitive firms, they are sometimes thought to be captives of the automobile makers. It may be that the makers rather than the dealers decide the inventory holdings of automobile dealers.

I have stressed repeatedly that the $S, s$ model has very different empirical implications from the stock-adjustment model. Table 13 helps to distinguish between the two models. It displays, for each retail sector, a decomposition of the variance of $Y$ around trend similar to that presented above for more aggregated data. Several generalizations can be made. First, except for the other durable goods sector, the variance of deliveries to retailers, $y$, exceeds the variance of retail sales, $x$. Second, the covariance between sales and inventory change is never a substantial negative number; it is either positive or virtually zero. These two facts make it very difficult to believe that the main role of retail inventories is to serve as a buffer stock. ${ }^{27}$ If firms want to use inventories to cushion $y_{t}$ against

27. In fact, it was data like these that first led me to investigate the $S, s$ model as an alternative to the buffer stock model. 
Table 13. Decomposition of the Variance of Deliveries to Retailers around Trend, by Sector, January 1959 to December 1980 $^{a}$

\begin{tabular}{lcccccc}
\hline \multicolumn{1}{c}{ Sector } & & & & & $\operatorname{var}(y)$ & $\operatorname{var}(\Delta n)$ \\
\cline { 6 - 7 } & $\operatorname{var}(y)$ & $\operatorname{var}(x)$ & $\operatorname{var}(\Delta n)$ & $2 \operatorname{cov}(x, \Delta n)$ & $\operatorname{var}(x)$ & $\operatorname{var}(x)$ \\
\hline All retailing & 1.620 & 1.320 & 0.134 & 0.1410 & 1.15 & 0.10 \\
Durables & 0.794 & 0.636 & 0.088 & 0.0824 & 1.25 & 0.14 \\
$\quad$ Automobiles & 0.454 & 0.332 & 0.074 & 0.0491 & 1.37 & 0.22 \\
$\quad \begin{array}{l}\text { Furniture and } \\
\quad \text { appliances }\end{array}$ & 0.009 & 0.007 & 0.002 & 0.0090 & 1.31 & 0.24 \\
$\quad$ Lumber and & & & & & & \\
$\quad$ hardware & 0.023 & 0.021 & 0.001 & 0.0015 & 1.10 & 0.06 \\
$\quad$ Other durables & 0.013 & 0.017 & 0.003 & -0.0007 & 0.76 & 0.19 \\
Nondurables & 2.600 & 2.030 & 0.370 & 0.0919 & 1.28 & 0.18 \\
$\quad$ Food & 0.047 & 0.044 & 0.003 & -0.0004 & 1.07 & 0.06 \\
$\quad$ Apparel & 0.010 & 0.008 & 0.003 & -0.0003 & 1.35 & 0.39 \\
$\quad$ General merchandise & 0.067 & 0.041 & 0.019 & 0.0051 & 1.65 & 0.47 \\
$\quad$ Other nondurables & 0.046 & 0.044 & 0.006 & -0.0023 & 1.06 & 0.14 \\
\hline
\end{tabular}

Source: Same as table 12 .

a. Sales and deliveries are in billions of dollars, at monthly rates.

fluctuations in $x_{t}$, it seems odd that $\operatorname{var}(y)>\operatorname{var}(x)$. It seems even odder, if inventories are primarily a buffer, that $\Delta n$ and $x$ do not covary negatively.

\section{SALES EXPECTATIONS}

The model requires that sales be divided into expected and unexpected components. I started with a variety of proxies for expectations. However, since they all led to roughly the same results, I report equations based on only one. Specifically, in the estimates presented here, firms are assumed to estimate (or know) a demand curve,

$$
X_{t}=a(L) X_{t-1}+b(L) P_{t}+c(L) P I_{t}+\text { error }
$$

where the first term is a fourth-order distributed lag on past sales, the second is a distributed lag on the industry's relative price (relative to the personal consumption deflator), and the third is a distributed lag on real personal income. ${ }^{28}$ The $b(L)$ and $c(L)$ parameters were estimated initially as free distributed lags, with lags going back as far as one year.

28. In fact, equation 25 was estimated on detrended data, and then the trend component of sales was added back. 
Then, using a series of $F$-tests, the lag length was reduced if there was no deterioration in the fit.

In order to use 25 to generate forecasts, it is necessary to forecast the contemporaneous values of relative price and real personal income. Relative prices are forecast by an autoregression. Personal income is forecast in two ways: by an autoregression and by an autoregression supplemented by publicly available macroeconomic forecasts. Two sources of real GNP forecasts were tried: the consensus forecast of the National Bureau of Economic Research-American Statistical Association and that of Wharton-Econometric Forecasting Associates, Inc. ${ }^{29}$ However, I found that neither forecast was a significant determinant of $P I$ after controlling for $P I_{t-1}, P I_{t-2}, \ldots$ For this reason, the macro forecasts were discarded, and personal income was predicted by an autoregression. ${ }^{30}$

\section{INTEREST RATES}

One long-standing problem in the empirical inventory literature has been the inability to uncover significant interest rate effects, even though every theory of inventory holding insists that they should be present. ${ }^{31}$ The usual intertemporal substitution variable in optimizing models of inventory behavior (and the $S, s$ model is no exception) is the so-called own real interest rate, that is, the nominal interest rate minus the expected rate of inflation of the firm's product. The reason for this is quite straight-

29. In each case I interpolate monthly forecasts from the quarterly data. I would like to thank Victor Zarnowitz for providing the NBER-ASA forecasts and Jeffrey Green for providing the Wharton forecasts.

30. The other proxies for expectations were simpler. One was a fourth-order autoregression in sales-that is, equation 25 with $b(L)$ and $c(L)$ constrained to zero. The other was the retailer proxy forecast, a simple rule of thumb suggested by Irvine. See F. Owen Irvine, Jr., "Retail Inventory Investment."

31. See, however, a series of recent papers on the subject by F. Owen Irvine, Jr.: "The Influence of Capital Costs on Inventory Investment: Time Series Evidence for a Department Store," Quarterly Review of Economics and Business, forthcomir $\rightarrow$ "Merchant Wholesaler Inventory Investment and the Cost of Capital," American Economic Review, vol. 71 (May 1981, Papers and Proceedings, 1980), pp. 23-29; and "Retail Inventory Investment." See a $\rightarrow$ Laura S. Rubin, "Aggregate Inventory Behavior: Response to Uncertainty and Interest Rates," Journal of Post Keynesian Economics, vol. 2 (Winter 1979-80), pp. 201-11; and Charles Lieberman, "Inventory Demand and Cost of Capital Effects," Review of Economics and Statistics, vol. 62 (August 1980), pp. 348-56. 
forward. A decision to hold a finished good in inventory for one period entails forgoing the current price, $P_{t}$, today to receive the expected future price, $P_{t+1}^{e}$, one period later. If the nominal interest rate is $i_{t}$, the effective cost of this storage activity (ignoring explicit storage costs) is

$$
\frac{\left(1+i_{t}\right) P_{t}-P_{t+1}^{e}}{P_{t}}=\left(1+i_{t}\right)-\left(1+\pi_{t}\right)=i_{t}-\pi_{t},
$$

where $\pi_{t}$ is the anticipated rate of nominal capital gain. Therefore intertemporal substitution can be captured by including $i_{t}-\pi_{t}$ in the equation.

However, there is at least one theoretical consideration that points toward using the nominal interest rate instead. Many retailers (and perhaps manufacturers as well) are thought to follow a first in, first out (FIFO) pricing strategy: once a finished good is placed on the shelves, it is given a price tag that remains on the item regardless of what subsequently happens to the price of newly produced goods. Everyone has at one time or another bought some durable good that was the last one at a given price because the next shipment would have higher priced merchandise. To many economists the rationality of this practice has seemed dubious. But Arthur Okun recently suggested that FIFO pricing may be rational when there are long-standing customer relations. ${ }^{32}$ If FIFO pricing really is prevalent, the real interest rate is not the appropriate intertemporal price. If a firm pays $i_{t}$ to hold a commodity in inventory but does not earn the price appreciation, $\pi_{t}$, when it sells the commodity (because the old price tag remained on the commodity), the nominal interest rate is the "correct" cost of capital. For this and other reasons, I use the nominal interest rate and the expected rate of inflation as separate variables rather than using the difference between them. ${ }^{33}$

What about taxes? Suppose first that the real interest rate specification is the correct one. Since inventories of retailers are, by definition, part of their normal business, price appreciation on inventory holdings is tax-

32. Arthur M. Okun, Prices and Quantities: A Macroeconomic Analysis (Brookings Institution, 1981), pp. 155-60. Okun also made the intriguing suggestion that the desire to use a FIFO pricing strategy (so as not to break a trust with the firm's regular customers) may explain why firms use FIFO accounting.

33. For discussion of these other reasons and some evidence that the coefficients of $i_{t}$ and $\pi_{t}$ are not equal and opposite, see Irvine, "Merchant Wholesaler Inventory Investment." 
able as ordinary income under FIFO accounting. So the real after-tax cost of capital under FIFO is

$$
\left(1-\tau_{t}\right)\left(i_{t}-\pi_{t}\right)
$$

where $\tau_{t}$ is the marginal corporate income tax rate. But if firms use last in, first out (LIFO) accounting, they can essentially escape taxation on their nominal capital gains, making the cost of capital

$$
\left(1-\tau_{t}\right) i_{t}-\pi_{t}
$$

Finally, suppose the nominal interest rate specification is the correct one because firms are FIFO pricers. Then the relevant after-tax cost of capital would be

$$
\left(1-\tau_{t}\right) i_{t}
$$

Since the statutory corporate income tax rate has been changed only slightly (and infrequently) since 1959, not much is lost by treating $\tau$ as constant in empirical work. Once this is done, all three versions of equation 26 can be handled by simply allowing the nominal rate of interest and the expected rate of inflation to enter the regression separately as determinants of $\eta$, and embedding the factor $(1-\tau)$ in the appropriate slope coefficients.

The nominal interest rate is measured by the bank prime lending rate. Expected inflation rates are obtained by fitting autoregressions to the levels of absolute prices in each sector, using these to compute onemonth-ahead forecasts, and then converting the forecasts into monthly inflation rates. (The prime rate is also entered as a monthly rate.)

\section{MANUFACTURERS'PRICES}

Among the variables that the $S, s$ model suggests should influence the target inventory range is the ratio of the manufacturers' selling price, $c_{t}$, to the retailers' selling price, $p_{t}$. This ratio is computed separately for each sector by matching up the retail sectors with corresponding components of the producer price index. (The matchup is presented and discussed in appendix C.) Relative prices were normalized to 1.00 in 1972. 


\section{STOCK-ADJUSTMENT REGRESSIONS}

Before looking at the empirical results for my rather unconventional model of inventory behavior, it may be useful to investigate first what happens when these data are used to estimate a standard stock-adjustment model. I argued above that this model lacks a persuasive theoretical rationale for retailers and that the coefficient of $N_{t}$ will be afflicted by leastsquares bias if the $S$, $s$ model is correct.

Table 14 displays estimates of the stock-adjustment model described in equation 4 for all retailing and for eight subsectors:

$$
N_{t+1}-N_{t}=\lambda\left(N_{t}^{*}-N_{t}\right)-\beta X_{t}^{u}+\epsilon_{t},
$$

where

$$
N_{t}^{*}=a+b X_{t}^{e}+c_{1} i_{t}+c_{2} \pi_{t},
$$

which together imply

$$
\begin{aligned}
Y_{t}=\lambda a & +(1+\lambda b) X_{t}^{e}+(1-\beta) X_{t}^{u}-\lambda N_{t} \\
& +\lambda c_{1} i_{t}+\lambda c_{2} \pi_{t}+\epsilon_{t} .
\end{aligned}
$$

Several observations summarize the results. First, the model does rather well in goodness of fit, ${ }^{34}$ but in some sectors (especially automobiles) there is an indication of autocorrelation in the residuals. Second, the estimates of $\lambda$, the speed of adjustment, are totally implausible. The highest is merely 0.14 ( 14 percent a month!) while the lowest is 0.03 . These simply do not make sense. Third, the coefficients of expected and unexpected sales are sometimes quite close together. ${ }^{35}$ This finding makes little sense in the context of equation 27 since the coefficient of $X_{t}^{e}$ should

34. This is hardly surprising with trend-dominated data. However, even when the regressions were performed on detrended data, the $R^{2}$ ranged from 0.66 to 0.95 .

35. By a standard $F$-test, the null hypothesis that the coefficients of expected and unexpected sales are equal-that is, that only actual sales appears on the right-hand side-can be rejected in only four of the eight sectors. It can, however, be argued that there is an econometric bias when expectations are measured with error. This would bias the coefficient of unexpected sales toward the coefficient of expected sales. The argument is fully presented in J. David Germany, "Unanticipated Money Growth, Inventories, and the Business Cycle" (Ph.D. dissertation, Massachusetts Institute of Technology, July 1981), chap. 2. 


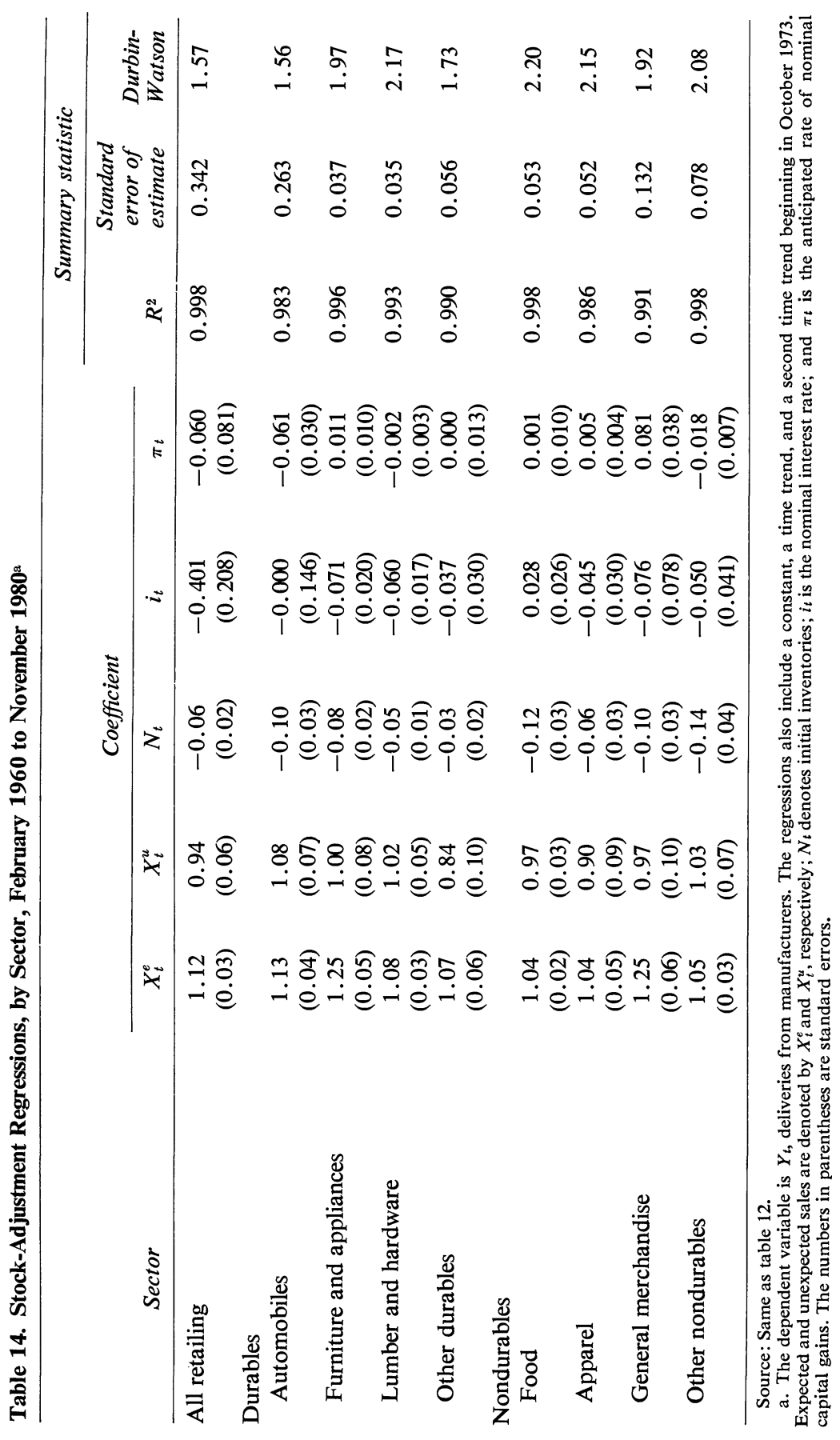


exceed the coefficient of $X_{t}^{u}$ by $\lambda b+\beta$. Fourth, interest rate effects are of the correct (negative) sign in all sectors except one, but are significant in only two sectors. ${ }^{36}$ And fifth, the expected rate of inflation performs much worse, with the correct (positive) sign in only four of the eight sectors and a significantly positive coefficient only for general merchandising. The hypothesis that the coefficients of the nominal interest rate and the inflation rate are equal and opposite, in other words, that it is the real rate of interest that matters, does not seem to hold for any sector except general merchandise.

The $S, s$ model offers an explanation of the puzzling results found in these tables and also provides a way to assess the quantitative importance of the aforementioned least squares bias. The regressions in table 14 seem to suggest a simple model of the form

$$
Y_{t}=A X_{t}+B N_{t}+\text { error, }
$$

with $A$ somewhat larger than unity and $B$ a small negative number. Viewed as estimates of equation 27 , these results do not make much sense. But suppose instead that the data were generated by the $S, s$ model. Could one then make sense of the parameter estimates?

To answer this question, consider a simplified version of the $S, s$ model-equations 18 and 19-in which $K_{1}=K_{2}$ (so that only $X_{t}$, not its division into $X_{t}^{e}+X_{t}^{u}$, matters) and in which $u_{t}$ is zero every period: ${ }^{37}$

$$
\begin{gathered}
Y_{t}=K_{1} X_{t}+K_{3}\left(\eta_{t+1}-\eta_{t}\right)+\epsilon_{t} \\
N_{t}=b X_{t}+\eta_{t} .
\end{gathered}
$$

It is a straightforward but tedious computation to use 29 and 30 to calcu-

36. Because the interest rate coefficient in these tables shows the effect of the monthly rate of interest (in percentage points) on the monthly rate of deliveries, it also shows (approximately) the effect of the annual rate of interest on the annual rate of deliveries. For example, in the equation for all retailing in table 14, the -0.401 coefficient means that a 1 percentage point rise in the nominal interest rate would decrease annual deliveries by $\$ 401$ million at annual rates.

37. This is not really legitimate. I do it only for the following reason. If $u_{t}$ were included, all the expressions I present below would have complicated additional terms involving the variance of $u_{t}$ and its covariances with other variables. These expressions are always of indeterminate sign, and so it is never clear how they would affect the results presented here. 
late the variances and covariances among the variables $X, Y$, and $N$, and then to put these into the standard formulas for the ordinary least squares regression coefficients in 28 . The results are:

$$
\begin{aligned}
& \operatorname{plim} \hat{A}=K_{1}+(1-\rho) b K_{3} \\
& \operatorname{plim} \hat{B}=-(1-\rho) K_{3},
\end{aligned}
$$

where $\rho$ is the simple correlation coefficient between $\eta_{t+1}$ and $\eta_{t}$. Recall that I have argued that $\rho$ should be close to 1.0. If $\rho$ is high, then $\hat{B}$ in equation 28 is a badly biased estimate of $-K_{3}$ while $A$ in 28 is a nearly unbiased estimate of $K_{1}$. These a priori notions seem quite consistent with the empirical results, which show small negative $B$ and $\hat{A}$ in excess of unity. In summary, if the $S, s$ model is correct, the least squares bias afflicting 28 could well be strong enough to produce the results that were actually found..$^{38}$

\section{$S$, $s$ MODEL REGRESSIONS}

The $S, s$ model derived above is represented as model 0 and model 1 by equations 23 and 24 for model 0 and model 1 , respectively. To these are added, for empirical purposes, $z_{t}=\eta_{t+1}-\eta_{t}$ and

$$
\eta_{t+1}=\alpha_{1} i_{t}+\alpha_{2} \pi_{t}+\alpha_{3}\left(\frac{c_{t}}{p_{t}}\right)+v_{t+1}
$$

The equations are clearly nonlinear in the parameters, and so were estimated by nonlinear least squares. Results for model 0 and model 1 are reported in tables 15 and 16, respectively. Before looking at the details, some broad generalizations are possible.

First, the fit of the equations is quite good, despite their small $R^{2}$. The left-hand variable in these regressions is inventory investment, $Y_{t}-X_{t}$, whereas in the stock-adjustment regressions it was just $Y_{t}$. Hence the standard errors of the two sets of regressions are comparable, not their $R^{2}$. The standard errors in tables 15 and 16 are almost as low as those in table 14 despite the absence of the variable $N_{t}$ from the $S, s$ regressions. ${ }^{39}$

38. But see note 37 .

39. I have just argued that $N_{t}$ is correlated with the error term and hence is not a legitimate regressor. 


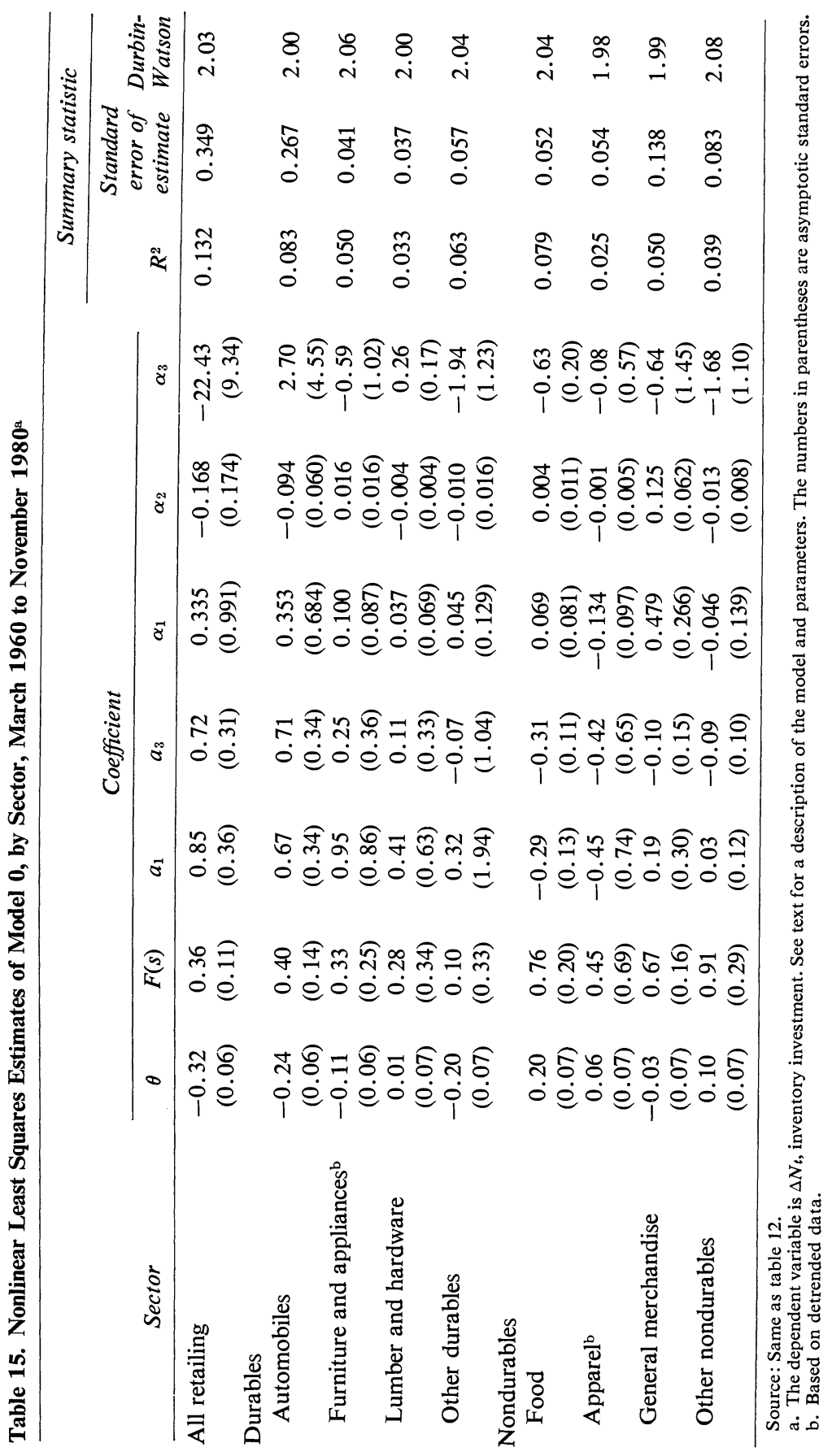




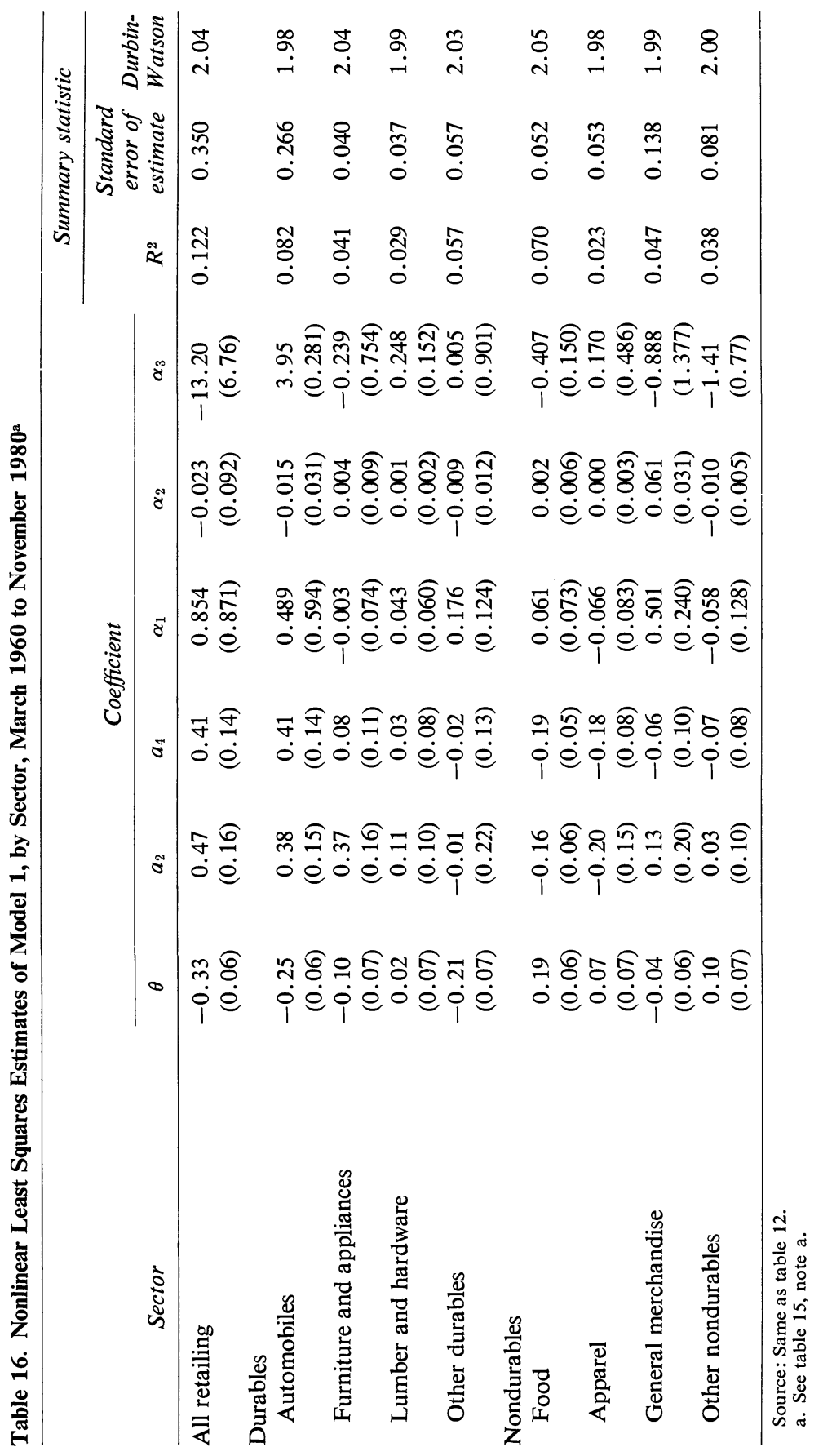


Second, there is a surprising absence of serial correlation in the residuals. In terms of the underlying model, this suggests either that $\epsilon_{t}$ can be modeled well as a random walk or that the variance of $\epsilon_{t}$ is trivial compared to the variance of $v_{t}$ (which, in turn, is nearly a random walk). Third, estimates using other proxies for expectations (not reported here) show that the parameters are quite insensitive to the way expectations are measured. Fourth, those parameters that are common to the two models (such as $\theta$ ) have more or less the same point estimates in model 0 and model 1.

I turn now to the parameter estimates, beginning (because it is slightly simpler) with model 1 , which assumes that changes in interest rates, cost conditions, and so forth always move $S$ and $s$ equally.

The most important parameter in the model is $\theta$, which was defined in equation 12 . The one restriction on $\theta$ is that $1+\theta>0$, and all the estimates easily satisfy this restriction. As indicated in figure 2 , a priori reasoning cannot determine the sign of $\theta$, but does suggest that very large negative $\theta$ are unlikely. In fact, the estimate of $\theta$ is positive in four sectors and negative in the other four. None of the point estimates seems implausible. Note that $1+\theta$ is analogous to the speed-of-adjustment parameter in the stock-adjustment model. ${ }^{40}$ In these estimates, $1+\theta$ ranges from 0.67 to 1.19 . These are quite rapid monthly adjustment speeds.

Unlike the parameter $\theta$, which arises from the aggregation process and has no counterpart at the micro level, the parameters $a_{2}$ and $a_{4}$ do have clear economic interpretations. Each is like a marginal inventory-sales ratio. Specifically, $a_{2}$ is the marginal effect on $S$ and $s$ of a unit increase in expected sales, and $a_{4}$ is the corresponding effect of a unit increase in unexpected sales. Hence one expects each to be positive and, if some inventories are required for display purposes, to be less than the average inventory-sales ratio.

Viewed from this perspective, most of the estimates of $a_{2}$ are reasonable. The $\hat{a}_{2}$ never exceeds the average inventory-sales ratio (which was reported in table 12). Of the nine cases in the table, $\hat{a}_{2}$ is positive in six; the only really bothersome sector appears to be food, where the estimated $a_{2}$ is significantly negative. The results for $a_{4}$ are not as good. The estimated $a_{4}$ is always below the average inventory-sales ratios, but $\hat{a}_{4}$ is negative in five of nine cases, including all the nondurable goods sectors.

40. Experiment 2 above shows that one unit of unwanted inventories leads firms to reduce orders by $1+\theta$ units. 
Parameter $\alpha_{1}$ measures the marginal effect of the monthly rate of interest in percentage points on the steady-state inventory level (see equation 31). It obtains the correct (negative) sign in only three sectors and is never significantly negative. One cannot help wondering whether the positive coefficients do not reflect reverse causation (borrowing to finance inventory investment raises the prime rate). But, in any case, the coefficients are all quite small. For example, the coefficient of approximately 0.85 in the all-retailing equation in table 16 means that a 1 percentage point rise in the annual rate of interest (a $1 / 12$ th percentage point rise in the monthly rate of interest) adds about $\$ 71$ million in 1972 dollars to steady-state retail inventory stocks. This is a trivial sum.

The results for the expected rate of inflation (parameter $\alpha_{2}$ ) are no better. Here the theoretically correct (positive) sign emerges in five of the nine cases, but the only sector that yields a correctly signed and statistically significant inflation effect is general merchandise. The coefficient is trivially small, however. It implies that a 1 percentage point rise in the steady-state annual rate of inflation would add only about $\$ 5$ million to the steady-state level of inventory holdings.

Finally, the impact of the nominal interest rate is generally far stronger than that of the expected rate of inflation. This reinforces a priori expectations and also the findings of Irvine. ${ }^{41}$

The last parameter, $\alpha_{3}$, indicates the impact of the ratio of buying prices to selling prices (that is, the retailer's margin) on desired inventory stocks. This variable, $c_{t} / p_{t}$, has the correct (negative) sign in the aggregate and in four of the eight sectors, and its effect is roughly statistically significant in the aggregate and in the food and other nondurable sectors. More important, the estimated effects are large enough to be economically important. The point estimate of roughly -13.2 for retailing as a whole means that a rise of 0.1 in the ratio of buying to selling prices (roughly a 10 percent decline in retailers' margins) reduces inventory investment by $\$ 884$ million at a monthly rate, or $\$ 10.6$ billion at an annual rate in the first month. This is a substantial impact. However, the effect dwindles, and the ultimate effect of a permanent decline of 0.1 in $c_{t} / p_{t}$ is to reduce steady-state inventories by only $\$ 1.32$ billion.

A much briefer description of the estimates of model 0 (table 15) can be given because most of the parameters are common to the two models.

41. See Irvine, "Merchant Wholesaler Inventory Investment and the Cost of Capital." 
The $\theta$, for example, has virtually the same point estimates in the two models. ${ }^{42}$

The important new parameter is $F(s)$, which has no counterpart in model 1 and provides another test of the model's validity because values outside the $(0,1)$ range are theoretically inadmissible. In fact, all nine of the point estimates fall comfortably within this range, and many differ significantly from both 0 and 1 .

In this model, $a_{1}$ and $a_{3}$ play the role of marginal inventory-sales ratios, but their interpretations are slightly different from $a_{2}$ and $a_{4}$ in model 1 . Specifically, $a_{1}$ indicates the marginal effect on $S$ of a unit increase in expected sales, and $a_{3}$ indicates the corresponding effect of a unit increase in unexpected sales. Here, because $s$ is held fixed, $a_{1}$ and $a_{3}$ are analogous to double the marginal inventory sales ratio, ${ }^{43}$ and so one expects them to be about twice as large as $a_{2}$ and $a_{4}$ in model 1 . In a rough way the point estimates confirm this expectation. Using the standard that $a_{1}$ and $a_{3}$ should always be less than twice the average inventory-sales ratio, no instances are found in which either $a_{1}$ or $a_{3}$ is too large. However, just as in model 1, negative values of $a$ are common in the nondurable sectors.

The interest rate and relative price variables do not perform any better in model 0 than in model 1.

Econometric results such as these are always like bottles half full and half empty. My own view is that the results are, on balance, favorable to the model. Unlike the stock-adjustment regressions, where almost none of the estimated parameters make sense in the light of the theory, most, though certainly not all, of the estimated parameters of the $S, s$ model are consistent with the underlying theory.

42. However, model 0 , unlike model 1 , has convergence problems in several sectors. I believe this is due to extreme multicollinearity in the data. To avoid the problem, I estimate the model 0 equation for the furniture and appliances and apparel sectors with detrended (and hence far less collinear) data. The results with detrended data are reported in table 15 for these two sectors.

43. If inventories were distributed uniformly on the interval $[s, S]-$ a condition not implied in the present model-average inventories would be

$$
\bar{N}=s+\frac{S-s}{2} .
$$

Thus with $s$ fixed the marginal inventory sales ratio would be

$$
\frac{\partial \bar{N}}{\partial \bar{X}}=\frac{1}{2} \frac{\partial S}{\partial \bar{X}}=\frac{1}{2} a_{1}
$$




\section{ADDITIONAL TESTS}

A number of further tests of the model yield generally favorable results. First, the model is estimated with detrended data, with results that are quite similar to those presented here. Hence the estimates are not dominated by common trends. Second, an examination of equations 23 and 24 -along with equation 31 , which defines $\eta_{t}$ - shows that while 24 is exactly identified, 23 is overidentified, reflecting the fact that both $z$ and $\Delta z$ are included in the equation. Specifically, as compared to an unconstrained linear regression, model 0 places two overidentifying restrictions on the data. These restrictions can be tested directly by a standard $\chi^{2}$-test. ${ }^{44}$ When this is done, the overidentifying restrictions are never rejected; the data and the model are compatible.

One final issue is worth exploring. Recall that the central parameter $\theta$ is defined as $\theta \equiv(S-s) f(s)-(1-F(s))$, where $f(\cdot)$ is the density function of $Q=N-X$ and $F(\cdot)$ is the corresponding cumulative distribution function. There is no reason to think that $\theta$ is constant through time. Yet, as an expedient to permit estimation, $\theta$ has been assumed to be constant.

I have tried only one way to improve this procedure by allowing $\theta$ to depend on some observable variable. My candidate is last period's sales surprise, $X_{t-1}^{u}$, which should have important effects on this period's initial inventories, $N_{t}$. The problem is that there is no a priori notion about which way this effect might go. On the one hand, a positive sales surprise makes some firms carry fewer inventories into the next period than they would otherwise. On the other hand, firms that are pushed below the $s$ trigger point by the sales surprise take more inventories into the next period. The net result is unclear.

Nonetheless, as an experiment, I ran a set of regressions for each model on the assumption that $\theta$ depends linearly on $X_{t-1}^{u}$, namely,

$$
\theta=\theta_{0}+\theta_{1} X_{t-1}^{u} \text {. }
$$

Since $\theta$ appears in almost all the slope coefficients in 23 and 24, this amendment complicates the estimating equations. Rather than show a

44. The $\chi^{2}$-test for nonlinear regressions is described in Stephen M. Goldfeld and Richard E. Quandt, Nonlinear Methods in Econometrics (Amsterdam: NorthHolland, 1972), p. 74. 
Table 17. Estimated Equations for the Automobile Industry, with and without the $\theta_{1}$ Parameter $^{\mathrm{a}}$

\begin{tabular}{|c|c|c|c|c|c|}
\hline \multicolumn{3}{|c|}{ Model 0} & \multicolumn{3}{|c|}{ Model 1} \\
\hline \multirow{2}{*}{$\begin{array}{l}\text { Parameter and } \\
\text { summary } \\
\text { statistic }\end{array}$} & \multicolumn{2}{|c|}{ Estimate $^{\mathbf{b}}$} & \multirow{2}{*}{$\begin{array}{l}\text { Parameter and } \\
\text { summary } \\
\text { statistic }\end{array}$} & \multicolumn{2}{|c|}{ Estimate $^{\mathrm{b}}$} \\
\hline & With $\theta_{1}$ & Without $\theta_{1}$ & & With $\theta_{1}$ & Without $\theta_{1}$ \\
\hline$\theta_{0}$ & $\begin{array}{r}-0.24 \\
(0.06)\end{array}$ & $\begin{array}{c}-0.29 \\
(0.06)\end{array}$ & $\theta_{0}$ & $\begin{array}{r}-0.25 \\
(0.06)\end{array}$ & $\begin{array}{c}-0.32 \\
(0.06)\end{array}$ \\
\hline$\theta_{1}$ & $0.00^{\mathrm{c}}$ & $\begin{array}{c}-0.00038 \\
(0.00013)\end{array}$ & $\theta_{1}$ & $0.00^{\mathrm{c}}$ & $\begin{array}{c}-0.00039 \\
(0.00010)\end{array}$ \\
\hline$F(s)$ & $\begin{array}{c}0.40 \\
(0.14)\end{array}$ & $\begin{array}{c}0.82 \\
(0.48)\end{array}$ & $\ldots$ & $\ldots$ & $\ldots$ \\
\hline$a_{1}$ & $\begin{array}{c}0.67 \\
(0.34)\end{array}$ & $\begin{array}{c}0.41 \\
(0.30)\end{array}$ & $a_{2}$ & $\begin{array}{c}0.38 \\
(0.15)\end{array}$ & $\begin{array}{c}0.56 \\
(0.17)\end{array}$ \\
\hline$a_{3}$ & $\begin{array}{c}0.71 \\
(0.34)\end{array}$ & $\begin{array}{c}0.41 \\
(0.27)\end{array}$ & $a_{4}$ & $\begin{array}{c}0.41 \\
(0.14)\end{array}$ & $\begin{array}{c}0.55 \\
(0.16)\end{array}$ \\
\hline$\alpha_{1}$ & $\begin{array}{c}0.353 \\
(0.684)\end{array}$ & $\begin{array}{c}0.694 \\
(0.620)\end{array}$ & $\alpha_{1}$ & $\begin{array}{c}0.489 \\
(0.594)\end{array}$ & $\begin{array}{c}0.733 \\
(0.570)\end{array}$ \\
\hline$\alpha_{2}$ & $\begin{array}{c}-0.094 \\
(0.060)\end{array}$ & $\begin{array}{r}-0.017 \\
(0.032)\end{array}$ & $\alpha_{2}$ & $\begin{array}{c}-0.015 \\
(0.031)\end{array}$ & $\begin{array}{c}-0.035 \\
(0.033)\end{array}$ \\
\hline$\alpha_{3}$ & $\begin{array}{c}2.70 \\
(4.55)\end{array}$ & $\begin{array}{c}3.75 \\
(3.69)\end{array}$ & $\alpha_{3}$ & $\begin{array}{l}3.95 \\
(2.81)\end{array}$ & $\begin{array}{c}5.87 \\
(2.95)\end{array}$ \\
\hline $\begin{array}{c}\text { Standard error } \\
\text { of estimate }\end{array}$ & 0.267 & 0.263 & $\begin{array}{l}\text { Standard error } \\
\text { of estimate }\end{array}$ & 0.266 & 0.260 \\
\hline $\mathbf{R}^{2}$ & 0.083 & 0.114 & $\mathrm{R}^{2}$ & 0.082 & 0.132 \\
\hline Durbin-Watson & 2.00 & 2.02 & Durbin-Watson & 1.98 & 2.08 \\
\hline
\end{tabular}

Source: Same as table 12.

a. See table 15 , note a.

b. Asymptotic standard errors are in parentheses.

c. Constrained.

complete set of results-which, for the most part, look just like tables 15 and 16-I simply report that the $\chi^{2}$-test rejected the null hypothesis $\theta_{1}=0$ for all retailing and for the automobile sector, but for no other sector.

Examination of the estimated equations (not reported here) shows that the parameter estimates for the all-retailing sector changed little even though $\theta_{1}$ was significantly negative (meaning that a positive sales surprise last period reduces this period's $\theta$ ). However, the estimates for the automobile sector did change noticeably. Because this industry is so important in terms of cyclical activity, table 17 compares the regression results with and without the extra parameter $\theta_{1}$. In model 0 the parameter 
$F(s)$ rises from 0.40 to 0.82 , and the parameters $a_{1}$ and $a_{3}$ fall from 0.67 , 0.71 to $0.41,0.41$, respectively. Parameter changes in model 1 are smaller.

\section{Inventory Behavior in 1979 and 1980}

Can the events of 1979-80 be explained using this knowledge of inventory behavior? As will be seen, the $S, s$ model is not quite up to the task, although it does better than the stock-adjustment model.

Table 18. Real Inventory Investment, 1979:1 to 1980:4

Billions of 1972 dollars

\begin{tabular}{rrc}
\hline Year and quarter & Entire economy & Retail sector $^{\mathrm{b}}$ \\
\hline $1979: 1$ & 15.4 & 0.0 \\
2 & 18.4 & 6.0 \\
3 & 7.6 & -1.1 \\
4 & -0.7 & -5.3 \\
$1980: 1$ & -0.9 & -7.5 \\
2 & 1.3 & -0.6 \\
3 & -5.0 & 1.3 \\
4 & -7.2 & -1.9
\end{tabular}

Sources: Data for the entire economy are from the national income and product accounts; the retail sector is based on unpublished data from the Bureau of Economic Analysis.

a. At seasonally adjusted annual rates.

b. Aggregated from monthly data.

There are three main puzzles about inventory behavior during the 1979-80 episode (see table 18). First, real inventory investment peaked in 1979:2, a full three quarters before real GNP peaked, and then troughed in 1980:1, which was the GNP peak. By contrast, inventory investment has typically peaked in the same quarter as GNP, or perhaps one quarter before, in previous recessions. The second puzzle is that inventory investment rose (slightly) during the recession, which is somewhat unprecedented. And the third is that inventories were liquidated while sales were expanding briskly in the second half of 1980 .

Much of this unusual behavior of aggregate inventory investment can be traced to retail inventory investment. Clearly, both the decline in inventory investment from 1979:2 to 1980:1 and the rise from 1980:1 to $1980: 2$ came mainly from the retail sector. However, the sharp turn toward liquidation late in 1980 did not come from retailing, where inven- 
tory stocks were fairly constant after March. Hence I focus on the 1980 recession period and on the first two puzzles.

Two hypotheses about inventory behavior during the recession appear frequently in the news media but receive little support from the data. According to the first of these, firms suffered so much during the 1973-75 recession that they permanently changed their inventory management techniques and kept their inventories trimmer relative to sales than previously. The other hypothesis agrees that inventory management procedures changed permanently during the 1970s but attributes the shift to computerization rather than to the recession. ${ }^{45}$

The data do not support these hypotheses, however. Figure 3 shows the time series behavior of the inventory-sales ratio in retailing; the downward deflection at OPEC-1 was quite trivial. The picture for the entire economy is even more damaging to the hypothesis. The ratio of real inventories to final sales shows a pronounced downward trend until about 1966, a pronounced upward trend between 1966 and 1970, and no trend since then. Inventory-sales ratios have averaged about the same since OPEC-1 as they did between 1969 and 1973.

An alternative hypothesis is that the 1980 recession, unlike earlier recessions, was forecast far in advance. (Indeed, many forecasters were predicting a recession a year or more before it actually began.) As a consequence, firms kept inventories lean and did not experience the traditional surprising drop in sales that leads to an unwanted buildup in inventories and a subsequent liquidation. According to this hypothesis, it was the absence of any need to liquidate inventories at the trough that enabled the economy to get through what was actually a severe recession in terms of final sales with such a small rise in unemployment and in such a short time. The data in table 18 seem quite consistent with this hypothesis, especially for retailing. Note in particular that inventories were being reduced sharply even though final sales were growing in 1979:4 and 1980:1. This behavior seems consistent with the idea that retailers were anticipating a recession.

To tell the story of $1979-80$ in terms of the model, I use the time series on expected sales, $X_{t}^{e}$, and unexpected sales, $X_{t}^{u}$, to generate the predicted values of inventory investment from the equations in table 14 for the

45. On the latter, see Lewis Beman, "A Big Payoff from Inventory Controls," Fortune, July 27, 1981, pp. 76-80. 
Table 19. Retail Sales and Inventory Investment, April 1979 to June $1980^{\mathrm{a}}$

Millions of 1972 dollars

\begin{tabular}{|c|c|c|c|c|c|c|}
\hline \multirow[b]{3}{*}{ Year and month } & & & \multicolumn{4}{|c|}{ Inventory investment } \\
\hline & \multicolumn{2}{|c|}{ Sales } & \multicolumn{4}{|c|}{ Prediction } \\
\hline & $\begin{array}{c}\text { Actual, } \\
X_{t}\end{array}$ & $\begin{array}{c}\text { Unexpected } \\
X_{t}^{u}\end{array}$ & $\begin{array}{c}\text { Actual, } \\
\Delta N_{t}\end{array}$ & $\begin{array}{c}\text { Stock- } \\
\text { adjustment } \\
\text { model }\end{array}$ & $\begin{array}{c}\text { Model } \\
0\end{array}$ & $\begin{array}{c}\text { Model } \\
1\end{array}$ \\
\hline 1979, April & 46,646 & -360 & 348 & 106 & 190 & 174 \\
\hline May & 46,800 & 301 & 731 & -8 & 180 & 188 \\
\hline June & 46,312 & -296 & 429 & -18 & 496 & 462 \\
\hline July & 46,422 & 195 & 1,064 & -88 & 177 & 163 \\
\hline August & 47,620 & 883 & -86 & -146 & 301 & 322 \\
\hline September & 48,223 & 626 & $-1,262$ & -95 & -225 & -132 \\
\hline October & 47,125 & -646 & 477 & 43 & -263 & -160 \\
\hline November & 47,389 & 262 & -483 & -149 & 161 & 179 \\
\hline December & 47,565 & 273 & $-1,313$ & -89 & -133 & -105 \\
\hline 1980, January & 47,997 & 900 & $-1,048$ & -90 & -561 & -511 \\
\hline February & 46,917 & -714 & -538 & 94 & -197 & -98 \\
\hline March & 45,482 & -927 & -291 & -89 & -178 & -54 \\
\hline April & 44,225 & $-1,383$ & 276 & -124 & 18 & -83 \\
\hline May & 43,880 & -487 & -296 & -249 & 13 & -204 \\
\hline June & 44,407 & 73 & -130 & -179 & -123 & -143 \\
\hline
\end{tabular}

Sources: Actual sales and inventory investment are based on unpublished data from the Bureau of Economic Analysis; model predictions, on simulations by the author.

a. Monthly rates.

stock-adjustment model, table 15 for model 0 , and table 16 for model 1 . However, since the evidence indicates that $X_{t-1}^{u}$ was a significant determinant of $\theta$ in all retailing and in the automobile sector, the equations having this augmented specification were used for these sectors.

Table 19 shows what actually happened to retail sales and inventory investment between April 1979 and June 1980, which seems to be the interesting period, and what the three models predict.

The table gives two overall impressions: first, that none of the models does a very good job of accounting for inventory behavior during this period (even though it was part of the sample period); second, that the stock-adjustment model behaves quite sluggishly. It seems quite incapable of predicting large inventory movements even when there are large sales surprises.

The period from April to July 1979 was one of rapid inventory accumulation by retailers, and table 19 shows that this accumulation was 
poorly predicted by all the models. The stock-adjustment model predicts no net change in inventory levels during these months. The $S, s$ model does far better, but still underpredicts the amount of accumulationespecially in July, when the equation residuals are about $2 \frac{1}{2}$ standard errors. Thus there was some unusual inventory accumulation going on during these months, especially in July. Disaggregated data show that a good deal of this unusual behavior was accounted for by automobile dealers, though other retailers were heavily involved in June and July.

August 1979 was, according to my expectations measure, a period in which there was a big, positive, sales surprise. In view of how large and how abrupt the sales increase was, the amount of inventory liquidation was quite small in the aggregate (although automobile inventories declined more). The stock-adjustment model does fairly well here, while the $S, s$ model misses by about one standard error.

In September 1979 there was another positive sales surprise according to my model, and inventory decumulation was severe. In fact, virtually all of this astonishingly large inventory disinvestment ( $\$ 15.1$ billion at an annual rate) was done by automobile dealers, and the equations do not predict this behavior at all. Sales then dropped sharply in October and inventories accumulated-suggesting involuntary inventory investment. None of the models captures this behavior.

The most stunning and, from the point of view of the 1980 recession, most significant behavior occurred in December 1979 and January 1980. In December, although sales were strong and fairly well predicted, inventories were drawn down at an astounding rate ( $\$ 15.8$ billion at annual rates). A good deal of this disinvestment, once again, came from the automobile industry. The equations do not capture this liquidation well; residuals are over two standard errors. Then, in January 1980, sales shot upward rapidly and, according to the model, unexpectedly. The rate of inventory decumulation in January exceeds the rate of unexpected sales, which suggests involuntary disinvestment. The $S, s$ models do reasonably well in predicting this disinvestment, but the stock-adjustment model misses it entirely.

Then sales went sour after February 1980, and the recession was on. According to the model, the declines in sales in February, March, and April were mostly unexpected. And casual observation of what went on during this time buttresses this view. (Recall that the Federal Reserve enforced credit controls in March 1980, and final sales went into a tail- 
spin.) Despite this, retailers managed to trim inventories in February and March and accumulated only in April. The $S, s$ model predicts this behavior better than the stock-adjustment model, but none does very well.

Thus retailers appear to have shed inventories rapidly both in December 1979 (for reasons that are unclear) and in January 1980, mostly because sales spurted ahead unexpectedly. As a consequence, they entered the recession with very low stocks. In addition, they were able to trim inventories further in February and March - which they wanted to do, according to the $S$, $s$ model-even though sales were collapsing. Thus, when final sales bottomed out in May 1980, retailers were not loaded with excess inventories, and so the painful inventory liquidation that normally prolongs and deepens recessions did not have to take place.

What features of this episode, then, were predictable from the models and what features are unexplained? One largely unexplained phenomenon is the high rate of stock building from April to July 1979, and especially in July. It may well have been a mistake that retailers rectified with rapid inventory decumulation in September.

But the main event in table 19 is surely the huge inventory liquidation in December 1979 and January 1980. Less than a third of this is predicted by the $S, s$ model; almost none is predicted by the stock-adjustment model; and the rest is unexplained. Whatever its cause, this period of rapid inventory liquidation left retailers with lean stocks at the onset of the recession. In sum, the sharp drop in inventories in December 1979 and January 1980 (mostly automobiles), which was caused in part by a spurt in sales, may have prevented the 1980 recession from rivaling or even surpassing the 1973-75 recession.

\section{A Summing Up}

Inventory fluctuations are important in business cycles; indeed, to a great extent, business cycles are inventory fluctuations. A surprisingly large fraction of the variability of aggregate inventory investment comes from the retail sector; little comes from manufacturers' inventories of finished goods.

But retail inventory investment has received little empirical and theoretical attention. The empirical work that has been done on retail inventory behavior has generally adopted the stock-adjustment model that 
Michael Lovell designed for explaining manufacturing inventories. However well this model does in explaining manufacturers' inventories, it seems unsuited to retailing both on theoretical grounds (why should retailers want to smooth deliveries?) and on empirical grounds (the estimates do not make sense).

There is a workable alternative — the $S, s$ model —which has a long and venerable history in the operations research literature, and which is allegedly in common use in industry today. The difficulties of deriving aggregate implications from a model in which inventory behavior is so discontinuous, and the complex dynamics that the $S, s$ model implies, pose barriers to empirical implementation of the theory. This paper offers one way to overcome these barriers.

The empirical model described here as a representation of the $S, s$ theory-equations 23 and 24-may not be the only one possible, but it is a beginning. When it is applied to the data, most of the estimated parameters are consistent with the implications of the theory.

The estimates presented in tables 15 and 16 offer an alternative interpretation of the anomalous results obtained with stock-adjustment models that suggests far faster speeds of adjustment; they do not offer much support for the view that inventory investment is highly sensitive to the cost of capital; and they indicate a rather low sensitivity of $S$ and $s$ to current sales, whether expected or unexpected. ${ }^{46}$

AP PENDIX A

\section{Comparative Statics of the Analytical Model}

THE EXPRESSION for aggregate deliveries, equation 11 in the text, is repeated here for convenience:

$$
\bar{Y}=(S-s) F(s, \gamma)+\int_{s-X_{1}}^{s} F(Q, \gamma) d Q
$$

46. An open question is whether the estimated sensitivity of $S$ and $s$ to sales is too small from the point of view of the theory. This cannot be addressed until there is some explicit $S$, $s$ theory for a nonstationary world. 
where the vector of parameters $\gamma$ has been added because some of these parameters affect the distribution function $F(Q)$.

The first comparative statics experiment considered in the text was a uniform rightward shift of the distribution of sales by $\gamma_{1}$ units (an increase in demand). Since $Q=N-X$, such a change would shift the distribution function of $Q_{t}$ uniformly to the left by $\gamma_{1}$ units, that is, from $F(Q, 0)$ to $F\left(Q, \gamma_{1}\right)=F\left(Q+\gamma_{1}, 0\right)$. Thus for an infinitesimal move of $\gamma_{1}$,

$$
\frac{\partial F\left(Q, \gamma_{1}\right)}{\partial \gamma_{1}}=f\left(Q+\gamma_{1}\right)
$$

Evaluated around $\gamma_{1}=0$, this is

$$
\frac{\partial F(Q)}{\partial \gamma_{1}}=f(Q)
$$

Such a shift leaves $S, s$, and $\bar{N}$ unchanged and moves $\bar{X}$ and $X_{1}$ by one unit. Using all this information in taking the derivative of equation 11 leads to

(A-1) $\frac{\partial \bar{Y}}{\partial \gamma_{1}}=(S-s) f(s)+\int_{s-X_{1}}^{s} f(Q) d Q=(S-s) f(s)+F(s)$,

which is equation 12 in the text.

Comparative statics experiment 2 in the text considered a uniform rightward shift in the distribution of initial inventories, $N_{t}$, with no change in the distribution of $X_{t}$ and no change in $S$ or $s$.

For convenience, I calibrate the shift parameter $\gamma_{2}$ so that $d \bar{N} / d \gamma_{2}=1$. Since the random variable $Q_{t}$ is the difference between $N_{t}$ and $X_{t}$, the effect of $\gamma_{2}$ on $F(Q)$ is equal and opposite to the effect of $\gamma_{1}$ on $F(Q)$, that is,

$$
\frac{\partial F(Q)}{\partial \gamma_{2}}=-\frac{\partial F(Q)}{\partial \gamma_{1}}=-f(Q)
$$

Using this information in equation 11 leads to

$$
\frac{\partial \bar{Y}}{\partial \gamma_{2}}=-(S-s) f(s)-F(s) \equiv-(1+\theta),
$$

which is equation 13 in the text. 
The next shift parameter to be considered is $\gamma_{3}$, which raises $S$ and $s$ equally but has no effect on the distributions of either $N_{t}$ or $X_{t}$, and hence no effect on $f(Q)$. It follows directly from equation 11 that

$$
\frac{\partial \bar{Y}}{\partial \gamma_{3}}=(S-s) f(s)+F(s) \equiv 1+\theta,
$$

which is equation 14 in the text. Equations 15 and $15 \mathrm{a}$ are derived similarly.

\section{APPENDIX B}

\section{Derivation of the Estimating Equations}

THE $u_{t}$ can be eliminated from equation 18 as follows. Solve equation 19 for $u_{t}$ and take the difference forward to obtain $u_{t+1}-u_{t}$. Then use the accounting identity to replace $N_{t+1}-N_{t}$ by $Y_{t}-X_{t}=Y_{t}-X_{t}^{e}-X_{t}^{u}$, and simplify. The result is:

$$
\text { (B-1) } \begin{aligned}
(1+\theta L) u_{t+1}= & -b X_{t+1}^{e}+\left(K_{1}-1+b\right) X_{t}^{e}+\left(K_{2}-1\right) X_{t}^{u} \\
& +\left(K_{3}-1\right) z_{t}+\epsilon_{t},
\end{aligned}
$$

where $L$ is the lag operator and $z_{t}=\eta_{t+1}-\eta_{t}$. This is the exact definition of $u_{t}$.

Next subtract $X_{t}$ from both sides of equation 18 to obtain

$$
Y_{t}-X_{t}=\left(K_{1}-1\right) X_{t}^{e}+\left(K_{2}-1\right) X_{t}^{u}-(1+\theta) u_{t}+K_{3} z_{t}+\epsilon_{t},
$$

and apply the operator $(1+\theta L)$ to both sides of this equation. After some algebraic manipulations, this yields

$$
\begin{aligned}
\Delta N_{t}= & -\theta \Delta N_{t-1}+\left[K_{1}-1+b(1+\theta)\right]\left(X_{t}^{e}-X_{t-1}^{e}\right) \\
& +\left(K_{2}-1\right)\left(X_{t}^{u}-X_{t-1}^{u}\right)+K_{3}\left(z_{t}-z_{t-1}\right) \\
& +(1+\theta) z_{t-1}+\epsilon_{t}-\epsilon_{t-1} .
\end{aligned}
$$


Application of the assumptions of model 0 and model 1 gives equations 23 and 24, respectively, in the text.

\section{AP PENDIX C}

\section{Manufacturers' Price Indexes}

ONE VARIABLE used in the regressions is the ratio of the retailers' buying price (the manufacturers' selling price) to the retailers' selling price. Retail sales price indexes are available for each of the sectors (unpublished data from the Bureau of Economic Analysis), but there are no data on buying prices.

I attempted to match each retail sector with a corresponding producer price subindex designed to represent the buying price of that sector as follows:

\section{Retail sector}

All retailing

Durables

Automobiles

Furniture and appliances

Lumber and hardware

Other durables

Nondurables

Food

Apparel

General merchandise

Other nondurables
Manufacturing sector, producer price index

Finished consumer goods

Passenger cars

Furniture and household durables

Lumber and wood products

Finished consumer durables

Processed foods and feeds

Textile products and apparel

Consumer nondurable finished goods (other than food)

Consumer nondurable finished goods (other than food)

In most cases the match is quite good. One minor problem is that the producer price subindex matched to "other durables" is actually the price index appropriate to all durables; it does not remove the prices of automobiles, furniture and appliances, and lumber and hardware. A similar problem is that the index matched to "other nondurables" fails to remove the prices of apparel and general merchandise items.

There is, however, one problem that is much more serious. The pro- 
ducer price index matched to the general merchandise sector-nondurable finished goods excluding food-includes energy prices and hence must have little resemblance to the prices actually paid by department stores in the post-OPEC period. There is no easy solution to this problem. I tried to create a synthetic index by using this index for the preOPEC period and using the index for consumer finished goods excluding food and energy (but including durables) for the post-OPEC period. But this variable performed very poorly in the regressions. 


\section{Comments and Discussion}

Michael C. Lovell: Alan Blinder's paper constitutes a most useful contribution to the understanding of how fluctuations in retail inventories influence the business cycle. The primary innovation involves his attack on the difficult task of applying the $S, s$ ("two-bin" or "optimal lot size") operations research inventory model pioneered by T. M. Whitin to the econometric study of inventory fluctuations over the course of the business cycle. ${ }^{1}$ This is not an easy task; I want to stress at the outset that the $S, s$ approach Blinder is taking is one that many economists have shied away from because it seemed intractable.

Blinder begins with a description of the substantial contribution that fluctuations in inventory investment make to cyclical reversals in the pace of economic activity. His results, for the most part, verify with recent data points made long ago by Abramovitz and Stanback about the large swings in inventory investment that take place in the typical business cycle. ${ }^{2}$ The fact is well known and suggests that the invisible hand that allocates research activity among competing topics, at least until very recently, provided too little support for the study of inventory cycles.

Blinder's strategy in demonstrating the fundamental role of inventories in the business cycle is to compare the variance of inventories about trend with that of other GNP components about their trend, taking covariances appropriately into account. A possible limitation of this strategy is that, while seasonal movements and trend have been eliminated, the irregular

1. Thomson M. Whitin, The Theory of Inventory Management (Princeton University Press, 1953).

2. Moses Abramovitz, Inventories and Business Cycles (National Bureau of Economic Research, 1950); and Thomas M. Stanback, Jr., Postwar Cycles in Manufacturers' Inventories (National Bureau of Economic Research, 1962). 
and cyclical movements are confounded; the variances and covariances reported in his tables do not confirm that the fluctuations are occurring at cyclical frequencies. My feeling is that a more revealing strategy, pioneered by Klein and Popkin twenty years ago, is to show with econometric model simulations how the economy would have behaved if inventories were stable. ${ }^{3}$ But although the analytic technique used by Blinder may be flawed, there is no questioning the fact that fluctuations in inventory investment normally play a large part in the typical business cycle downturn.

The latest recession appears as a possible exception to the classic pattern of inventory behavior. This is no surprise because there is a recurrent tendency as each recession passes for the preliminary data to suggest exceptional behavior. It is also usual in a recession for at least one business analyst to remark that the deviations from past cyclical patterns of inventory behavior result from the adoption of scientific inventory management techniques and improved computer control. Blinder found such remarks in Fortune; unfortunately, there is no obvious source of hard data with which to measure the spread of scientific inventory management. The surprise Blinder emphasizes is the fact that inventory investment was up in 1980:2. This was an upward movement in which the two preceding quarters and the following quarters were characterized by substantial decumulation; real inventory disinvestment took place at an annual rate of $\$ 5$ billion during the third quarter of 1980 , which marks the bottom of the National Bureau of Economic Research's reference cycle; inventory investment was negative for the year. The most unusual feature of this downturn is that it was so widely anticipated; indeed, the chairman of the Federal Reserve Board said the recession was half over before the cycle peaked! And the Federal Reserve imposed credit controls shortly after the recession finally materialized. From the preliminary evidence now available I do not think it is possible to determine whether the extremely short downturn was due to the atypical behavior of inventories, whether the extremely short nature of the downturn caused inventories to kehave strangely, or whether the apparent abnormality of

3. Lawrence R. Klein and Joel Popkin, "An Econometric Analysis of the Postwar Relationship between Inventory Fluctuations and Changes in Aggregate Economic Activity," in Joint Economic Committee, Inventory Fluctuations and Economic Stabilization, 87 Cong. 1 sess. (U.S. Government Printing Office, 1961), pt. 3, pp. $71-89$. 
behavior - the upward movement in the second quarter-was due to measurement error. ${ }^{4}$

I now turn to the heart of the paper, Blinder's application of the $S, s$ inventory model of operations research fame to the task of explaining aggregate inventory behavior. This is a most useful contribution, and I suspect that Blinder's approach may well find future applications in the area of manufacturing inventory as well as retail trade. In many manufacturing enterprises machine setup costs induce manufacturers to make extended runs of each different type of item they produce; the same square-root linkage between carrying costs and sales and the optimal order points applies to the determination of optimal lot size in manufacturing.

Both the pluses and minuses must be considered in comparing the $S, s$ approach with the rival behavior generated by certainty-equivalence linear decision rules derived from quadratic cost functions by Holt, Modigliani, Muth, and Simon. ${ }^{5}$ An advantage of linear decision rules is that they are linear, facilitating both their aggregation and their estimation in econometric applications. One disadvantage is that they are insufficiently restrictive; instead of yielding tight a priori restrictions limiting the range of admissible types of behavior that must be considered by the econometrician, this strategy can be used to justify a very wide variety of models as being compatible with the assumption of profit maximization. A second disadvantage of a linear decision rule is that although it can be used, once derived, to calculate on the back of an envelope the appropriate level of output, a painful recalculation of the rule is required to take changes in carrying costs (such as interest rates) properly into account. This makes it difficult for the econometrician using linear decision rules to model the effect of tight interest rates; it may also mean that business enterprises using linear decision rules will be slow to respond to interest rate changes because they will be reluctant to call in their consultants to do the $z$-transform calculations necessary to rederive the de-

4. Judging by past experience, GNP data are subject to sharp revisions. For example, the earliest published figures suggested that the 1958 recession involved a drop in GNP of $\$ 2.6$ billion; successive revisions changed this figure to $-\$ 0.800$, $+\$ 1.455,+\$ 1.777,+\$ 6.200$, and $+\$ 6.126$ billion. Quarterly data and figures on inventory investment (involving the differencing of observations of stocks) are subject to greater measurement error.

5. Charles C. Holt and others, Planning Production, Inventories and Work Force (Prentice Hall, 1960). 
cision rule. Further, the linear decision rule model does not tolerate the imposition of sign-constraints-for example, the restriction that stocks cannot be negative.

An advantage of the $S, s$ inventory rule is that it is rather easy to recalculate the trigger points in response to changes in sales volume or carrying costs. The $S, s$ firms are likely to be more responsive to interest rate changes. On the other hand, price adjustments are another story. Although it is reasonable for firms to reduce their customary markups when faced with exceptionally high inventory holdings, such behavior cannot be modeled within the $S, s$ framework with the same ease with which it can be added to the production smoothing model developed by Holt, Modigliani, Muth, and Simon. Indeed, an $S, s$ rule probably is not optimal once sales price is introduced as an additional decision variable.

The major disadvantage of $S, s$ decision rules is that aggregation is extremely difficult. Higher levels of management may be reluctant to adopt $S, s$ policies for individual product lines because it is difficult to determine their combined cash-flow implications. Further, it is conceivable that optimizing inventories on each product might lead to larger total inventories, leading company treasurers to reject the rules. The aggregation problem creates major difficulties for the econometrician interested in the industry-wide implications of $S, s$ inventory behavior; and the problem is confounded by the rich variety of responses that may be generated. For example, some firms may be inhibited by limited storage capacity from enlarging stocks in response to an increase in sales volume; this constraint has kept my neighborhood gasoline station from adjusting $S$ since long before OPEC. Some firms, at least in the longer run, may respond optimally by enlarging stocks in proportion to the square root of sales volume; in the still longer run, firms may respond to growing sales by introducing new product lines or adding new retail outlets, in which case stocks will expand in proportion to the growth in sales volume.

Blinder focuses upon two types of $S, s$ model response. In model 1 all firms in the industry respond to environmental changes by adjusting both $S$ and $s$ equally; in the simplest case, this means that the optimal order quantity remains constant while the safety stock changes. In model 0 the order quantity changes but the safety stock is fixed. These two models are marked simplifications of the many variations of the $S, s$ theme discussed in the management science literature. Some $S, s$ firms may continuously monitor their stocks and reorder at the precise instant their stocks hit the 
lower trigger point; others monitor at regular intervals, in which case the frequency of monitoring may be a decision variable. Nevertheless, I do not believe that Blinder should be faulted for his simplifications, which are obviously unavoidable because no model providing a framework for empirical study can attempt to capture the full detail of the complex phenomenon he is studying.

Blinder approaches the aggregation problem by evaluating simple simulation experiments based on four and sixteen single-product firms, each individually pursuing an $S, s$ inventory policy. My judgment is that Blinder does not go nearly far enough; a more elaborate research strategy is required. Artificial aggregate time series could be derived on the computer by summing data obtained from simulations run on 50 or 100 firms in a controlled experimental environment involving both demand shocks and shifting interest rates. Then Blinder could test his estimation strategy by determining how well it enabled an econometrician to recover the underlying firm parameters from the artificial aggregate time series. ${ }^{6}$ As it stands, Blinder's simple numerical calculations are suggestive, but $\mathrm{I}$ believe subsequent research must determine whether he has succeeded in accurately capturing the implications for the aggregates of the $S, s$ inventory behavior he postulates at the level of the individual firm.

Blinder's empirical tests contrast his $S, s$ model with the behavior of a naive buffer stock model of retail inventory behavior. The results for the two models are remarkably close in terms of goodness of fit, as measured by the standard error of the estimate. A major disappointment is that neither model provides any evidence for concluding that changes in interest rates or credit crunches have an impact on inventory investments, but as one of many researchers who has been similarly disappointed, I cannot cast stones at this nonresult.

My own view of the relative merits of the two models considered by Blinder is prejudiced by my own efforts in the area. I am unhappy with both. My worry with the buffer stock model does not arise primarily from the frequently voiced concern about slow speeds of adjustment. Effecting changes in inventory targets is likely to involve a delayed response in part because time may be required to do the arithmetic of changing $S, s$ trigger points or in applying the $z$-transform to rederive linear decision rules. A

6. This is the essence of the strategy employed in a pioneering study of inventory behavior by Edwin S. Mills, Price, Output, and Inventory Policy, a Study in the Economics of the Firm and Industry (Wiley, 1962). 
physical adjustment of storage capacity may be required-retail gasoline is an extreme example in which it is unlikely to pay the gasoline station to adjust storage capacity during the lifespan of the facility. For many retail stores, inventory consists of items with sharp seasonal fluctuations in demand. At the end of the summer the department store or discount house with sizable stocks of patio furniture is likely to have to carry over its inventory until next spring; that stock cannot be sold between Labor Day and Memorial Day. Retail outlets stocking hundreds of different items are likely to suffer from serious inventory imbalances-too many of last season's goods and not enough to meet current demands. Such imbalances cannot be rapidly adjusted except through distress sales, and these are ruled out by models that assume the retail price is exogenous, such as the $S$, $s$ model of optimal inventory behavior and Blinder's study, which treats the retailer's markup as exogenous. I think that the strategy pioneered by Modigliani and Sauerlender in their study of cement inventories could be fruitfully applied to retail trade. They allowed the speed of adjustment to become more rapid as the firm approached the end of the sales season. ${ }^{7}$

It seems to me that the speed of adjustment for inventories should be considerably slower than that for liquid assets; yet when the lagged stock of money is included in money demand equations, it generally has a rather large coefficient; for example, Steve Goldfeld obtains an adjustment speed of 25 percent per quarter for quarterly data on the demand for M1, which provides good company for the slow speeds of adjustment of many buffer stock inventory models. ${ }^{8}$ As is well known, lagged adjustment coefficients are subject to estimation bias. Some buffer stock models that include more refined specifications have yielded very fast adjustment speeds. Thus F. Owen Irvine, Jr., achieves an adjustment speed of 25 percent a month in recently published regressions on automobile inventories. ${ }^{9}$

In my judgment both the buffer stock and the $S, s$ models tested in Blinder's paper share a common defect because they neglect a funda-

7. Franco Modigliani and Owen H. Sauerlender, "Economic Expectations and Plans of Firms in Relation to Short-Term Forecasting," in National Bureau of Economic Research, Short-Term Economic Forecasting, Studies in Income and Wealth, vol. 17 (Princeton University Press, 1955). 686.

8. Stephen M. Goldfeld, "The Case of the Missing Money," BPEA, 3:1976, p.

9. F. Owen Irvine, Jr., "A Study of Automobile Inventory Investment," Economic Inquiry, vol. 19 (July 1981), pp. 353-79. 
mental point emphasized by Ruth Mack in much of her research: retailers must order seasonal merchandise long in advance of the sales season. They worry about Christmas in July; and the precise timing of deliveries is largely at the mercy of the manufacturer and the transportation network. Thus, Mack argues, the primary control variable to be watched by management is "ownership position," the sum of inventories on hand plus orders for merchandise yet to be delivered. ${ }^{10}$ Cyert and March provide support for Mack's position, pointing out that when advance orders are placed to cover only a fraction of the sales anticipated for the sales season, reordering on a rush delivery basis may involve a price penalty or the possibility that the item will never arrive, but the hope prevails that reordering can be tailored on an item-by-item basis, making use of sales experience early in the sales season. ${ }^{11} \mathrm{My}$ own research on retail inventories, based on individual department store stock and order data as well as aggregates, supports this approach..$^{12}$

A second problem is in the selection of proxies for anticipated sales. The one Blinder uses is based on an estimated demand equation incorporating the firm's relative price markup; this is inconsistent with his derivation of the $S, s$ policy rule, which assumes that the markup is exogenous to the firm. I believe that there are several promising expectations alternatives that deserve Blinder's attention. One is to note that retailers, because they do not have much skill in estimating seasonal movements, often resort to "same-period-last-year" forecasting; with monthly data, this suggests that sales lagged twelve periods may be an important component of anticipated sales. The second alternative is based on the extensive empirical evidence that sales forecasts are not fully rational; at least in manufacturing, firms do not adequately make use of their last period's sales in forecasting for next quarter; thus it is fruitful to proxy expected sales, $X_{t}^{p}$, by a mixture of last period's sales and actual developments:

$$
X_{t}^{p}=\lambda X_{t}+(1-\lambda) X_{t-1}
$$

10. Ruth P. Mack, "Changes in Ownership of Purchased Materials," in Joint Economic Committee, Inventory Fluctuations and Economic Stabilization, 87 Cong. 1 sess. (GPO, 1961), pt. 2, pp. 59-87.

11. Richard M. Cyert and James G. March, A Behavioral Theory of the Firm (Prentice Hall, 1963).

12. Michael C. Lovell, "Department Store Inventory, Sales, Order Relationships," in James S. Duesenberry and others, eds., The Brookings Model: Some Further Results (North-Holland, 1969), pp. 18-38. 
the evidence is that $\lambda$ lies far from the value of unity implied by the rational expectations assumption. ${ }^{13}$ Further, it might be useful to consider explicitly the span of future sales over several months in order to encompass the full sales season.

In conclusion, while it should be no surprise to anyone that Lovell is still prejudiced in favor of the strategies applied in earlier research, I do want to emphasize that if I do not completely accept the innovative application of the $S, s$ model that Blinder presents, I am convinced that his paper constitutes a most innovative contribution that will spark a number of follow-up investigations in the years ahead.

Lawrence H. Summers: Alan Blinder's paper makes a significant contribution to the literature on inventories. Rather than fiddling with tried and untrue specifications drawn from earlier work, he steps back and rethinks the underlying economics. The paper sets forth an alternative theory of aggregate inventory behavior that, it is argued, is superior in both the realism of its microeconomic foundations and its ability to explain macroeconomic fluctuations. Blinder's paper is exceptional in its careful attention to aggregation issues and thorough efforts to verify the robustness of conclusions. It is refreshing to see a piece of empirical macroeconomics that so clearly has the truth, rather than the technique, as its objective.

Blinder makes an overwhelming case for inventory investment as an important component of business cycle fluctuations. However, he is much less persuasive about the importance of retail inventories. The disaggregation of manufacturing inventories into three components ensures that much of their variation will be relegated to the "all other covariance terms" category. Similarly, this procedure will understate the relative importance of manufacturing finished goods. More fundamentally, I wonder about the meaning of the category "retail inventory." Finished goods are stored between the time they are finished and the time they are consumed. It is of relatively little economic significance whether the appliance that will someday be mine today sits in a wholesaler's warehouse or a retail store's showroom.

This point is exemplified by the automobile industry, which accounts for most of the variance in retail inventories. Is it of economic significance

13. Albert A. Hirsch and Michael C. Lovell, Sales Anticipations and Inventory Behavior (John Wiley, 1969), chap. 5, pp. 112-92. 
whether gas guzzlers are located in Dearborn or on dealers' lots? As many dealers can ruefully attest, retail inventories do not reflect retailer choices. To the extent that automobile inventories play an important role in business cycle fluctuations, one wonders which way the causality runs.

The paper discusses alternative theories of inventory behavior. Blinder's skepticism about the production-smoothing model as an empirically relevant tale about business cycles seems well warranted. Is not the following an acid test? If production-smoothing were the dominant consideration in cyclical inventory fluctuations, then one would see inventory buildups at cycle troughs and liquidation at peaks. The opposite is the case, however. The observation that production is more variable than sales is simply a more quantitative restatement of the same point. My doubts about the economic meaning of the inventory categories make me skeptical about the previous empirical tests of this model Blinder cites, which study only finished goods inventories in manufacturing. Manufacturers presumably induce retailers to buffer manufacturing inventory fluctuations by offering them price reductions.

Blinder then turns to an examination of the implications of his favorite theory, the $S, s$ model for aggregate economic behavior. Although the $S, s$ model is to operations research what the Phillips curve once was to economics, its macroeconomic consequences, to my knowledge, have never been studied. I have three major reservations about Blinder's otherwise excellent treatment. First, virtually all retailers sell a large number of goods obtained from a much smaller number of suppliers. The economies of scale to which Blinder refers, such as the fact that empty trucks are costly, are overcome by having large orders even if they are for several different goods. Order points for any given good should depend on available inventories of all goods. No reorder point can be fixed for one good independently. And it cannot be assumed that the $S$, $s$ model is applicable en masse to appropriate groups of goods. There is a major problem when one good is in short supply but other goods are not. This problem of aggregation across goods strikes me as being as important as the aggregation over firms to which Blinder devotes much more attention.

Second, Blinder tells a partial equilibrium tale in which a large number of prices are held fixed. As a model for analyzing the inventory decisions of a department store's inventory, the $S$, $s$ model can easily be rationalized. I doubt that it can be justified as a story about aggregate fluctuations, or at least not without a great deal more work. Consider a single supplier 
dealing with many retailers. If the economy takes a downward turn and all retailers foresee a prolonged shortfall in sales, demand for deliveries will respond sharply. Blinder's simulations provide an idea of what would occur. Deliveries would become very erratic. In Blinder's simplified example, the standard deviation of deliveries actually exceeds their mean. This would impose huge burdens in terms of either production variability or fluctuating inventories on suppliers. Presumably they would respond by changing prices in an effort to achieve a smoother production path. These changes in prices would introduce intertemporal substitution effects of a type not captured by the $S$, $s$ model. Firms would order early or delay slightly beyond the point suggested by the $S$, $s$ model in order to purchase at the time when goods were relatively cheap. The assumption that Blinder makes - that these sorts of effects do not exist in short-run business cycle fluctuations-is inconsistent with the theory. If the $S$, s model is really an accurate representation, fluctuating deliveries must necessarily give rise to this sort of response.

There is another way to look at this. Without specifying the details, micro theory allows us to assert that a competitive economy will minimize costs. Producers and retailers will reach the equilibrium that minimizes the sum of production, inventory holding, and inventory ordering costs. It does not matter whether or not producers own their retail outlets, the strategy that minimizes joint costs will be adopted. This result does not rest on any assumed cooperation between producers and retailers. Rather, it is grounded in the logic of profit maximization. Suppose a policy were followed that led to different marginal cost of inventory holding for producers and retailers. The producer would find profits increased by adjusting the price to the retailer until the point at which the equal marginal costs condition was met. This argument does not depend on the assumption of perfect competition in either producer market or in retailing. Similar arguments are standard in industrial organization, where they are invoked to demonstrate that even in situations of imperfect competition, there is no loss in efficiency from certain types of vertical arrangements. The details of a joint cost minimization strategy are difficult to articulate. In general, they depend on the magnitude of adjustment costs in production, on shipment costs, and on the relative costs of inventory holding by producers and retailers. But two negative conclusions are clear. First, the proper unit of preliminary analysis is total inventories, not those held by either producers or retailers. Second, the pattern of retail 
orders actually observed need not be anything like that predicted by the $S, s$ model with the false assumption of constant supplier prices.

The point here is the familiar fallacy of composition. Macroeconomic behavior is not fruitfully analyzed as the sum of the microeconomic behavior of each individual, with everything else held constant. I should emphasize that the fallacy of composition described here applies to all macroeconomic studies of inventory behavior that focus on only one type of market participant. It seems to me that the appropriate unit of analysis is aggregate inventories, rather than those held only by producers or retailers.

A third difficulty with the model Blinder employs is that it assumes that firms have no control over their sales, which they take as given, and that they expect to face a constant real price from suppliers. Anyone who has waited to buy a down jacket in May, a Christmas gift in January, or an old model car in September recognizes that retail inventories affect retail prices and sales. High department store markups further indicate the inelasticity of at least some retail demand. Even apart from the considerations just discussed, it is not reasonable to assume that real acquisition prices are constant. The tendency for prices to ratchet intermittently rather than rise continuously, which Blinder discusses, implies substantial gains to firms scheduling orders prudently.

These are not just quibbles. They are important channels of response to demand shocks in the form of changes in prices on the part of both suppliers and producers that need to be considered if inventory behavior is to be understood. Note that Blinder's finding that cost-of-capital effects are of no consequence is not relevant here. His analysis of the effects of interest rate changes is based on permanent changes that affect a firm's target range for inventories. The argument stressed here focuses on shortrun intertemporal substitution effects.

Given these theoretical difficulties, it is surprising that Blinder's empirical work turns out as well as it does. There are, however, several difficulties that should lead to caution in interpreting the results. First, Blinder uses seasonally adjusted data in all his regressions. Although I recognize the difficulties and costs of doing otherwise, I believe this is a mistake. Firms order when actual inventories are low, not when seasonally adjusted inventories are below some norm. They respond to sales rather than to deviations between sales and a seasonal norm. The theory is clearly couched in terms of actual levels, not seasonally adjusted levels. I cannot 
see any reason to expect the model to fit data smoothed by seasonal adjustment. There is another point here: I disagree with Blinder's judgment that inventory fluctuations that are purely seasonal are uninteresting. Their very regularity and size mean that they offer the best hope to identify the technological parameters that help to determine business cycle fluctuations.

Second, there are difficulties in Blinder's measurement of the cost of capital. In Blinder's formulation, the short-term interest rate enters into the determination of $\eta$. This is puzzling. The $S$ and $s$ should be set on the basis of long-run considerations rather than the very short interest rate that Blinder studies.

Third, there are potentially severe econometric problems with the results. Blinder notes the absence of serial correlation in his equations. This may well be the result of the inclusion of a lagged dependent variable. In the presence of a lagged dependent variable, conventional tests for serial correlation do not apply. Serial correlation leads to inconsistent, rather than merely inefficient, estimates. Moreover, there is every reason to expect complex moving-average errors given the sort of manipulations Blinder goes through to develop the estimating equation. Tests for firstorder autoregressive serial correlation seem insufficient. Moreover, it is questionable whether sales are really exogenous in an equation of this kind. The price effects I have just described, along with the "inventory cycle effects" that Blinder discusses, make this premise seem unlikely.

Despite these doubts, I believe this paper breaks important new ground. It suggests alternative formulations to the standard stock adjustment model of inventory behavior. And it goes a long way toward developing the implications of one plausible alternative, the $S, s$ model. It is clear that more useful research can be done within this framework. Such research will start with Blinder's important contribution.

\section{General Discussion}

Most of the discussants agreed with Blinder that further study of inventory behavior was worthwhile. Charles Holt lamented the lack of communication among economists, management scientists, and industrial engineers and observed that the management science literature had long ago recognized that production smoothing is a poor model for retail 
inventories. A number of discussants raised questions about the plausibility of Blinder's model. Several agreed with Summers that the $S, s$ model was not appropriate for the retail automobile sector that dominated retail inventory behavior. Holt suggested that since automobile inventories are largely controlled by manufacturers rather than retailers, another inventory model is needed that pays more attention to the relation between firms at different stages of production. Robert Gordon added that the average size of a delivery-probably six to eight cars per truckloadis much smaller than a retailer's typical monthly sales. For this reason it seemed unreasonable to believe the sawtooth pattern of inventory holdings implicit in the $S, s$ model. He questioned the relevance of a theory that does not apply to a major fraction of retail inventory fluctuations. Gordon also pointed out that, in sectors such as retail furniture, firms only make decisions regarding orders once or twice a year, and actual fluctuations in inventories after that are largely determined by sales and manufacturers' delivery schedules. Thus the timing of inventory fluctuations is not tightly tied to retailers' decisions.

Several discussants found the $S, s$ theory unrealistic in assuming that the retail price is outside the control of retailers. Stephen Goldfeld noted that price reductions are frequently used by retailers to adjust excess inventories. F. Thomas Juster added that, although price adjustment is probably unimportant in sectors such as food retailing, in others such as general merchandising, retailers simultaneously revise their price and inventory policies when they notice their sales are not meeting sales targets.

Martin Baily defended the production-smoothing model of inventory holdings in situations in which sales fluctuations are believed to be short term-seasonal sales fluctuations, for example. In a business cycle peak, sales start to fall and firms allow inventories to pile up because they think that the sales decline is temporary. Once it becomes clear that there will be a prolonged recession, firms cut production and work off excess inventories because it is too costly to use inventories to smooth production over a period as long as the business cycle. The end-of-expansion productivity behavior recently described by Robert Gordon is a closely related phenomenon. ${ }^{1}$ William Fellner in turn questioned the realism of the $S, s$ model. While agreeing that a minimum order size would introduce fluc-

1. See Robert J. Gordon, "The 'End of Expansion' Phenomenon in Short-Run Productivity Behavior," BPEA, 2:1979, pp. 447-61. 
tuations in the holdings of small retailers, he did not know the plausible reason for large firms to have deliveries that were sizable relative to monthly sales.

Discussants offered a variety of comments on the empirical work in the paper. Benjamin Friedman argued that the lag structure used by Blinder is implausible since it assumes a nearly instantaneous response by retailers to inventory excess or shortage and to changes in interest rates and prices. Friedman suggested that decisionmakers often do not find out about these changes within a month, so it does not seem sensible to assume that responses to them begin in the initial month. The fact that this assumption is usually made when estimating inventory models might explain the implausibly slow adjustment speeds found in studies using the stock-adjustment model, without any need to invoke the $S, s$ model.

Goldfeld was skeptical of Blinder's particular specification and interpretation of the inventory equation in light of Blinder's own simulations and rich menu of possible lag structures. He noted that except for the error term, the estimating equations look rather conventional. If the theory is to be taken seriously, much more attention should be given to the time structure of the error term. Holt noted that unfilled orders and the lead times required to replenish inventories vary cyclically and thought it a mistake to take them as constant in estimation. He also argued that the dynamics of aggregate inventory behavior is importantly affected by interindustry structure. In particular, he reported finding in a study of the television industry that this structure leads to important amplification effects, with small fluctuations in sales at the retail level leading to larger fluctuations for wholesalers and even larger fluctuations for manufacturers. Although production was smoothed, fluctuations of orders to suppliers were again amplified. Holt also observed that the introduction of computers has revolutionized inventory control and suggested that this should cause some instability in the coefficients of the inventory model through time.

Christopher Sims questioned whether the estimated equations actually constitute an identified structural model of businesses' inventory holding behavior. He believed that the equations are more likely simply to reflect the complex interrelation between inventories and other endogenous variables in the economy.

Gordon and Sims, while agreeing that there may be other reasons to investigate inventory behavior, disputed the importance of inventory 
fluctuations to business cycles. Gordon pointed out that only $61 / 2$ percent of deviations of GNP from trend are attributable to inventory fluctuations, and suggested that the main point of business cycle studies is to explain these deviations from trend. Sims observed that inventories might be important for determining the local timing of cycles, but in his own work "surprises" in inventories do not seem to lead to important cumulative effects on other macroeconomic variables. Consequently, precise modeling of inventories does not appear particularly important from the point of view of forecasting GNP four quarters ahead. William Branson countered that, in the current very serious recession in Britain, the entire reduction in GNP seems to be accounted for by inventory decumulation according to data in the paper by Buiter and Miller in this issue. Blinder suggested that inventory movements provided a major part of the explanation for normal recessions, but agreed with Gordon that very severe recessions or depressions-with the possible exception of the recent British experience-are not well explained by inventory behavior. 